NBER WORKING PAPER SERIES

\title{
THE IMPORTANCE OF PSYCHOLOGY IN ECONOMIC ACTIVITY: EVIDENCE FROM TERRORIST ATTACKS
}

\author{
Kenneth R. Ahern \\ Working Paper 24331 \\ http://www.nber.org/papers/w24331
NATIONAL BUREAU OF ECONOMIC RESEARCH
1050 Massachusetts Avenue
Cambridge, MA 02138
February 2018

I thank Fernando Anjos, Cary Frydman, Arjen Siegmann, Jose Tavares and seminar participants at the American Economic Association Annual Meeting, Nova School of Business and Economics, Texas A\&M University, University of British Columbia, and University of Porto. The views expressed herein are those of the author and do not necessarily reflect the views of the National Bureau of Economic Research.

NBER working papers are circulated for discussion and comment purposes. They have not been peer-reviewed or been subject to the review by the NBER Board of Directors that accompanies official NBER publications.

(C) 2018 by Kenneth R. Ahern. All rights reserved. Short sections of text, not to exceed two paragraphs, may be quoted without explicit permission provided that full credit, including () notice, is given to the source. 
The Importance of Psychology in Economic Activity: Evidence from Terrorist Attacks

Kenneth R. Ahern

NBER Working Paper No. 24331

February 2018

JEL No. E7,K42,O1,O43

\section{ABSTRACT}

Terrorist attacks influence economic growth and individual psychology. However, identifying the direct effect of terrorism on economics and psychology is difficult because institutions also change in response to terrorist attacks. This paper controls for institutional responses to terrorist attacks by studying people who live beyond the institutions' borders, but are exposed to the attacks. I find that terrorism leads to declines in trust, subjective well-being, and the importance of creativity and freedom. However, at the macro-level, terrorism leads to increases in economic output and household income. These results are consistent with a growing literature that finds counterintuitive responses to trauma.

Kenneth R. Ahern

Marshall School of Business

University of Southern California

3670 Trousdale Parkway, $\mathrm{HOH} 718$

Los Angeles, CA 90089

and NBER

kenneth.ahern@marshall.usc.edu 
Figure I shows that the number of terrorist attacks across the world has risen dramatically from 1,162 attacks in 2004 to a peak of 16,860 attacks in 2014. The sharp increase in terrorist attacks has potentially severe consequences for mental health, political stability, and economic growth. In particular, terrorist attacks cause increases in post-traumatic stress disorder, depression, and anxiety. ${ }^{1}$ They also alter institutions by changing political views (Gould and Klor, 2010), election outcomes (Montalvo, 2011), and political regimes (Gassebner, Jong-A-Pin, and Mierau, 2008). Finally, terrorism is associated with changes in macroeconomic outcomes, including decreases in GDP (Blomberg, Hess, and Orphanides, 2004), investment (Llussá and Tavares, 2011), and trade (Blomberg and Hess, 2006).

Given the rising influence of terrorism in society, it is important to understand the ways in which terrorism influences institutions and economies. Because few people are physically harmed by terrorist attacks, terrorism's primary channel of influence must be psychological. Exposure to a terrorist attack could change economic attitudes and political opinions, which leads to changes in institutions and economic behavior. However, attitudes, institutions, and economic behavior are intertwined. This makes it difficult to disentangle whether psychology impacts economic outcomes (Spolaore and Wacziarg, 2009), economic outcomes impact institutions (Aghion, Alesina, and Trebbi, 2004), or institutions impact psychology (Di Tella, Galiani, and Schargrodsky, 2007).

This paper studies the causal effect of terrorist attacks on individual psychology and macroeconomic outcomes while controlling for local institutional responses. First, using data from the European Social Survey for 21 countries from 2002 to 2011, I measure the change in individual psychology caused by the two largest terrorist attacks in European history: the 2004 Madrid train bombing and the 2005 London metro attacks. Individual psychology is measured by psychological traits related to economic choices, including cultural values, trust, subjective well-being, and attitudes towards free markets. In a difference-in-difference framework, I measure the change in the psychological traits of people closer to the attacks

\footnotetext{
${ }^{1}$ See Schuster et al. (2001), Galea et al. (2002), Rubin et al. (2005), and Gabriel et al. (2007).
} 
compared to people further from the attacks. I use two proxies to measure closeness to the attacks: 1) travel time to Madrid or London, and 2) language spoken at home (Spanish or English). People who speak Spanish or English are more likely to be exposed to greater media coverage of the events (Speckhard, 2003). To control for endogenous institutional responses, I study people who do not live in the country where the terrorist attack occurred, and hence, are not influenced by the institutional response to the attack.

The first set of results shows that the endogenous institutional response to terrorist attacks can obscure the effects on individual psychology. Without controlling for institutional responses, trust and egalitarian values increase following the London attack, but not the Madrid attack. The effect on well-being also varies between the Madrid and London attacks: subjective well-being decreases following the London attack, but chronic health problems decrease following the Madrid attack.

Once I control for institutional responses to the attacks by excluding respondents who live in Spain or the UK, the effects of terrorist attacks become clearer. Following both attacks, trust decreases, chronic health problems increase, subjective well-being decreases, and the importance of creativity and freedom decrease. Thus, terrorist attacks have significant detrimental impacts on individual psychological traits after controlling for endogenous institutional responses to terrorism.

In the second set of tests, I use a similar research design to measure the effect of terrorist attacks on macroeconomic outcomes. Because I study aggregated outcomes rather than individual psychology, I expand the sample of terrorist attacks to increase the power of the tests. In particular, for each of 91 sub-national regions in Europe from 1995 to 2008, I calculate the fraction of the foreign population that comes from countries which experienced an abnormally high level of terrorism in a given year. To record detailed citizenship status of a region's population, I use census microdata from the Integrated Public Use Microdata Series - International (IPUMS-I). I identify abnormally high levels of terrorism as years in which a country experiences more terrorism-related fatalities than the country's median number 
of fatalities during the previous five years. This controls for resilience among populations living in countries with greater levels of terrorism (Becker and Rubinstein, 2011).

In tests that control for regional fixed effects and region-specific time trends, but that allow for endogenous institutional responses, I find that exposure to terrorist attacks have a negative impact on GDP per capita and GDP growth, while the unemployment rate decreases and employee compensation increases. These results are consistent with prior studies (Blomberg, Hess, and Orphanides, 2004; Eckstein and Tsiddon, 2004), which suggest that the simultaneous decrease in output and increase in labor share may be explained by inefficient government spending following a local terrorist attack.

When I study regions not directly affected by a local terrorist attack, but whose population is affected by foreign attacks, I find strikingly different results. As a larger fraction of a region's population is exposed to terrorism in their home countries, the region's GDP per capita, GDP growth, and household income increase. In addition, the magnitude of these effects increases as terrorist attacks in expatriates' home countries become more deadly, providing evidence that the results are not spurious, but driven by exposure to terrorism. Robustness tests verify that the results are not caused by reverse causation, terrorism-induced immigration, or spillovers in institutional responses. These results provide suggestive evidence that the psychological impact of terrorism leads to improvements in macroeconomic outcomes, contrary to conventional wisdom.

My results are consistent with a growing literature that finds that exposure to violence has counter-intuitive effects. For example, Brück, Llussá, and Tavares (2011) report evidence that terrorist attacks increase entrepreneurial activities. Similarly, Voors, Nillesen, Verwimp, Bulte, Lensink, and Soest (2012) find that exposure to violence during the civil war in Burundi caused lasting increases in altruism, and decreases in risk aversion and patience. Other papers report increases in egalitarianism, altruism, and civic participation following exposure to violence in a wide range of settings, including Uganda, Sierra Leone, Nepal, and 
Georgia. ${ }^{2}$ However, while my research design helps to separate the effect of institutions from psychological changes, identifying the exact psychological mechanisms that cause positive changes in macroeconomic outcomes is challenging.

As one way to better understand the underlying psychological mechanisms, in the final part of the paper, I compare natural and technological disasters to terrorist attacks. Natural and technological disasters, such as earthquakes and accidental factory explosions, share many similarities with terrorist attacks. Each of these incidents involves a random, unexpected, and traumatic loss of life. However, only terrorist attacks are intentionally committed acts of violence by other people. Thus, the psychological impact on economic outcomes following terrorist attacks may differ from natural or technological disasters. For instance, a natural disaster might not affect trust because no person is to blame, whereas a terrorist attack could affect trust because the act was committed intentionally by another person. I find that terrorist attacks have a substantially larger impact on macroeconomic outcomes than do accidental disasters (roughly five times as large), even though disasters have higher numbers of fatalities, on average. These results are consistent with the idea that psychological views towards others, such as trust, have a stronger influence on economic outcomes than psychological views towards oneself, such as subjective well-being.

The central contribution of this paper is to provide new evidence of terrorism's effect on individual psychology and macroeconomic outcomes, controlling for endogenous institutional responses. This paper contributes to the literature that links macroeconomic outcomes with psychological traits, such as trust (Guiso, Sapienza, and Zingales, 2009; Knack and Keefer, 1997; Algan and Cahuc, 2010), cultural values (Barro and McCleary, 2003; Gorodnichenko and Roland, 2017; Tabellini, 2010), and subjective well-being (Di Tella, MacCulloch, and Oswald, 2001, 2003). This paper also contributes to the literature on the direct effects of terrorism on macroeconomic outcomes (Abadie and Gardeazabal, 2003; Blomberg and Hess,

$\overline{{ }^{2} \text { See Bellows }}$ and Miguel (2009), Blattman (2009), Bauer, Cassar, Chytilová, and Henrich (2014), and Gilligan, Pasquale, and Samii (2011). 
2006). Finally, this paper presents some of the first evidence that terrorism affects cultural values and beliefs, not just psychological disorders like PTSD and depression.

\section{Theoretical Framework and Definitions}

In this paper, I consider multiple dimensions of an individual's mental state, and denote them collectively as psychology. This includes cultural values, subjective well-being, and attitudes towards ideas typically associated with free markets.

\section{I.A. Cultural Values}

Cultural values, as defined in Guiso, Sapienza, and Zingales (2006), are fundamental beliefs that are passed from one generation to another relatively unchanged. In this paper, I focus on three cultural values: trust/distrust, collectivism/individualism and egalitarianism/hierarchy. Trust has been widely studied in economics and shown to affect a multitude of economic outcomes (Guiso, Sapienza, and Zingales, 2006). The second and third dimensions, collectivism and hierarchy, are the only two dimensions that are common across the majority of leading classification systems of cultural values (Fiske, 1991; Hofstede, 1980, 2001; Schwartz, 1994; Trompenaars, 1993). While other dimensions of cultural values are likely to affect economic behavior, by focusing on just these three dimensions, I am restricting attention to the most central and robust dimensions of culture.

First, trust is the willingness to rely on another to fulfill an obligation. Since contracts are necessarily incomplete, trust between economic agents reduces transaction costs and facilitates trade (Arrow, 1972; Zak and Knack, 2001). Empirical evidence supports this argument in a wide range of economic outcomes. At the same time, trust is likely to be affected by exposure to terrorist attacks. Both victims of domestic violence and children exposed to violence suffer from an inability to trust others (Carmen, Rieker, and Mills, 1984; Margolin and Gordis, 2000). Exposure to terrorism could have similar effects. However, 
there is evidence that trust could increase following exposure to terrorist attacks. Smith, Rasinski, and Toce (2001) report a slight increase in trust among U.S. residents after the 9/11 attacks, but lower averages for New York City residents.

Second, collectivism is the importance placed on group goals, as opposed to individualism, where individual aspirations are given greater priority. In collectivist cultures, individuals are rewarded for sacrificing individual achievement for the overall benefit of society (Brett, 2000). Tabellini (2008) presents a theoretical model that shows that collectivist social norms can arise endogenously and lead individuals to forgo individually-beneficial outcomes. Gorodnichenko and Roland (2017) presents evidence that individualism leads to greater innovation, productivity, and income.

Third, hierarchy refers to the variation in vertical social status in a society. More hierarchical cultures have greater separation of social status between social classes. Egalitarian societies have less differences between social classes. Bartling, Fehr, Maréchal, and Schunk (2009) present experimental evidence that a preference for egalitarianism leads participants to select less competitive tasks. Ahern, Daminelli, and Fracassi (2015) and Siegel, Licht, and Schwartz (2011) show that cross-border differences in egalitarianism affect foreign direct investment and cross-border mergers.

Though there is little existing evidence that terrorist attacks may alter views on collectivism and hierarchy, it is reasonable to expect that exposure to intentional random violence could change one's beliefs about social capital and the importance of equality. To the best of my knowledge, Murphy, Gordon, and Mullen (2004) is the only other study that uses preand post-terrorist attack survey responses to test for cultural value shifts. They find that following the 9/11 attacks in New York and Washington, people placed more emphasis on survival, safety, and security, and less on self-esteem and self-actualization. Somewhat related, Bonanno and Jost (2006) present evidence that political views shifted following 9/11. 
In post-attack surveys, they report that $9 / 11$ survivors shifted their political ideologies towards conservatism. This evidence suggests that terrorism may also affect people's views on the importance of cooperation and fairness.

\section{I.B. Subjective Well-Being}

While cultural values represent beliefs about how individuals should interact in society, subjective well-being (SWB), or happiness, reflects an individual's self-assessment of one's own mental state. SWB was first proposed by psychologists as a self-reported assessment of overall mental well-being. Since Easterlin (1974), a relatively small, but growing set of economics papers have used SWB as a measure of experienced utility, as an alternative to the more traditional revealed preferences decision-based concept of utility (Kahneman and Thaler, 1991; Kahneman, Wakker, and Sarin, 1997). In particular, SWB has been linked with GDP, income, unemployment, and inflation (Di Tella, MacCulloch, and Oswald, 2001, 2003; Stevenson and Wolfers, 2008). Di Tella and MacCulloch (2006) and Dolan, Peasgood, and White (2008) provide overviews of this literature.

Exposure to terrorism is likely to reduce happiness. Numerous papers in the psychology literature show that terrorist attacks have substantial impacts on mental health. Galea et al. (2002), Schulster et al. (2001), and Schlenger et al. (2002) all provide evidence that greater exposure to the $9 / 11$ terrorist attacks caused meaningful increases in symptoms of post-traumatic stress disorder, depression, and life-threatening perceptions. The only study, to my knowledge, that directly tests for changes in overall SWB following terrorist attacks is Frey, Luechinger, and Stutzer (2009), who find that terrorist attacks in France and Great Britain led to a significant decrease in happiness for residents in the regions where terrorist attacks occurred. 


\section{I.C. Attitudes Towards Free Markets}

Last, attitudes towards free market ideals are likely to affect economic activity. Though there is no definitive set of beliefs that are necessary for a capitalist society, the following three ideals appear to be important: 1) the value of creativity, 2) the importance of success and recognition, and 3) freedom of choice. In particular, capitalist societies reward innovation. Schumpeter's theory of creative destruction posits that innovation is the outcome of capitalist forces. Second, as suggested by Di Tella, Galiani, and Schargrodsky (2007), beliefs in meritbased rewards are important for capitalism. ${ }^{3}$ Finally, the third belief is that freedom of choice is important.

To my knowledge, no prior study has investigated the effect of terrorism on these beliefs. It is possible that terrorist attacks could lead people to prefer less freedom if it means greater security through government intervention in their daily lives. Thus, beliefs could become less capitalist. Alternatively, terrorist attacks could strengthen individualistic and self-interested beliefs. Thus, ideals associated with capitalism could be strengthened and economic outcomes improved.

\section{Research Design}

There are at least two challenges to identifying the effect of terrorism on individual psychology and macroeconomic outcomes. First, psychology or macroeconomic conditions could cause the likelihood of terrorist attacks to increase (reverse causation). Second, terrorist attacks could lead to institutional changes which affect both psychology and economic activity (omitted variables).

To address both of these potential identification problems, I study the effect of foreign, rather than local, terrorist attacks on local populations. This means that I use variation in local populations' exposure to attacks that occur in foreign countries to measure variation

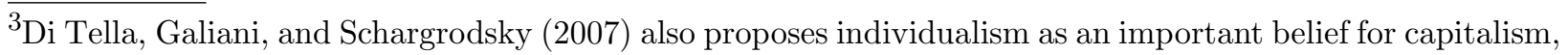
which I have included as one of three primary cultural values dimensions. 
in changes in psychology. Exposure to foreign terrorist attacks can occur through expatriate populations, geographic proximity, or common language, among other channels.

First, using attacks that occur abroad addresses reverse causation, where macroeconomic conditions lead to terrorism. Though terrorists prefer to make random and unpredictable attacks, prior research has found mixed evidence on the predictability of terrorism. Krueger and Laitin (2008) finds that wealthier countries are more likely to be targets of terrorism. Similarly, Blomberg, Hess, and Orphanides (2004) and Tavares (2004) find that terrorism is more common in higher income countries. In contrast, Abadie (2006) provides controls for reverse causation and finds that economic conditions are unrelated to the incidence of terrorism, a result confirmed by Gassebner and Luechinger (2011). Even when correlates have been identified, these studies emphasize that the explanatory power of their models is low. Nevertheless, there is still a concern that the location of terrorist attacks is not completely random. By investigating the effect of attacks that occur in a foreign country, I ensure that there is not a direct link between the economy of the local country and the likelihood of a terrorist attack in a foreign country. For example, it is not likely that terrorist attacks in Argentina are caused by GDP in Spain, where many Argentinians live.

Second, using attacks that occur abroad controls for local institutional responses to terrorism, which could drive macroeconomic changes. As noted in the introduction, terrorist attacks alter elections, shift political views, and contribute to regime changes. Direct responses to terrorism by governments also affect economic outcomes through changes in immigration and trade policies, as well as increased security measures (Di Tella and Schargrodsky, 2004; Gould and Stecklov, 2009; Draca, Machin, and Witt, 2011). Finally, terrorist attacks directly alter economic activity by influencing where people choose to work, conduct business, and how they travel (Blunk, Clark, and McGibany, 2006, Rubin et al., 2005). These institutional changes make it difficult to separate the role of psychology on economic activity from institutional effects. By using foreign attacks, I limit the likelihood that local governments respond to attacks in other countries. For instance, terrorist attacks in Argentina are 
likely to have psychological effects on Argentinians living in Spain, but are unlikely to affect Spanish institutions.

It is possible that governments could respond to foreign terrorist attacks. For instance, a terrorist attack in Ukraine could lead to institutional changes in Russia. A second concern is that foreign terrorism could cause emigration to Europe. In this case, macroeconomic outcomes would be the result of demography changes, rather than psychological changes. In later robust tests, I account for both institutional spillover and migration.

Finally, by using foreign attacks, I assume that expatriates are affected by terrorist attacks in their home countries. There is strong evidence to believe that they are. Expatriates could be affected by terrorist attacks through familial and personal connections with people in their home countries. In addition, expatriates are exposed to news stories and images of attacks in their home countries through foreign media sources. Empirical evidence is consistent with these ideas. Following the 9/11 attacks in New York, increases in psychological disorders were realized by people across the entire country (Seo and Torabi, 2004), as well as by U.S. citizens living abroad (Speckhard, 2003). Ahern et al. (2002) and Collimore et al. (2008) both find that greater media exposure to terrorism leads to stronger psychological reactions. However, expatriates are likely to have weaker responses to terrorist attacks in their home country than are people living closer to the attack. Expatriates do not directly experience the attack, as do locals, and may have few personal relations remaining in the country. Second, emigrates are self-selected, which means that expatriates are likely to have a weaker attachment to their home country than people that do not go abroad. In either case, less attachment will bias the impact of terrorist attacks on expatriates towards zero.

In summary, the identification strategy rests on the claim that terrorist attacks impact the psychology of those exposed and the assumption that terrorist attacks in foreign countries are exogenous to local GDP and institutions. I next empirically test the claim that exposure to terrorism impacts psychology. 


\section{The Impact of Terrorist Attacks on Psychology}

To test for an effect of terrorist attacks on psychology, I estimate the following model:

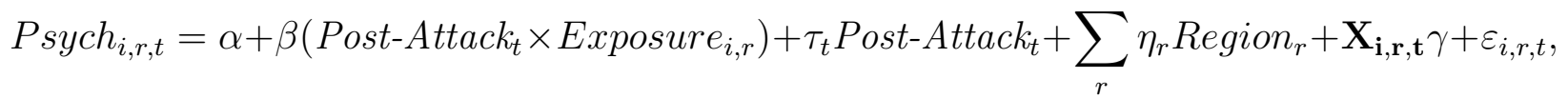

where $P s y c h i, r, t$ is a measure of the psychological state of individual $i$, residing in region $r$, at time $t$. Post-Attack $k_{t}$ is an indicator variable for the time period after a terrorist attack. Region $r$ is a set of geographic location fixed effect variables, and $\mathbf{X}_{\mathbf{i}, \mathbf{r}, \mathbf{t}}$ is a vector of individual-level control variables. The region fixed effects account for time-invariant differences in attitudes and cultural values across different geographic regions. The post-attack variable accounts for overall changes in psychological conditions for all people, independent of their proximity to the attack. The treatment variable is Exposure $e_{i, r}$, a measure of the intensity of exposure of the individual to the attack. I expect that individuals with greater exposure to the attack will realize greater changes in psychology post-attack, than will people with less exposure.

\section{III.A. Measures of Exposure to Terrorism}

The empirical strategy requires data on terrorist attacks and measures of exposure to the attack. First, I use the two most devastating terrorist attacks that occurred in Western Europe by number killed or injured: the Madrid train bombing in 2004 and the London metro attacks in 2005. During the morning rush hour of March 11th, 2004, a sequence of ten coordinated bombs exploded on Madrid's commuter system, killing 191 people and wounding over 1,800 others. Though the Basque separatist group Euskadi Ta Askatasuna (ETA) was initially blamed, the Spanish Judiciary eventually determined that the perpetrators were part of an Islamist extremist group (Hamilos, 2007). Though Spain had suffered prior terrorist attacks, primarily from ETA, the prior attacks typically targeted judges and the number of 
fatalities was limited to three to five people (National Consortium for the Study of Terrorism and Responses to Terrorism, 2011). Thus, the scale of destruction in the Madrid train bombing was unprecedented in Spain and in Western Europe overall.

The second most deadly terrorist attack in Western Europe is the " $7 / 7$ " bombing of the London public transport system on July 7th, 2005. Four suicide bombers detonated bombs in coordination on three different London Underground trains and one double-decker bus. Fifty-two people were killed and over 700 people were wounded in the attacks. These attacks were carried out by Islamist extremists, as well. Like Spain, Great Britain had experienced less severe terrorist attacks by the Irish Republican Army (IRA) in the past, but the impact of the $7 / 7$ bombings was an order of magnitude larger than that of prior attacks. ${ }^{4}$

Prior research finds that the Madrid and London terrorist attacks had significant effects on psychological health. Gabriel et al. (2007) finds that following the Madrid attacks in 2004, symptoms associated with post-traumatic stress disorder (PTSD), depression, agoraphobia, anxiety, and panic disorders all increased. Importantly, the increases were not limited to those physically injured by the attack, nor to people in Madrid. In particular, compared to a baseline of $0.9 \%$, the authors report an increase of $12.3 \%$ percentage points in symptoms of PTSD in the city of Alcala, about 35 kilometers outside of Madrid. Muñoz, Crespo, Pérez-Santos, and Vázquez (2004) finds similar results. The London attacks also led to widespread increases in anxiety and stress in the UK (Rubin et al., 2005). In addition, Bux and Coyne (2009) report that following the London attacks, retail sales fell by $8.9 \%$ and subway ridership dropped by up to $15 \%$.

I measure the exposure of an individual to the terrorist attack in multiple ways. First, I use indicator variables for individuals in Spain or Great Britain. The second measure of exposure is the log of the the number of hours it takes to drive from the center of region $r$ to either Madrid or London, calculated using Google Maps online driving direction application.

\footnotetext{
${ }^{4}$ In both cases, to the extent that prior histories of terrorist attacks in Spain and Great Britain made people more immune to psychological impact of terrorism, any results will be weakened.
} 
By calculating driving time, rather than simply using the great-circle distance calculated from longitude and latitude, this measure accounts for natural barriers that have historically separated geographic regions, such as mountain ranges or large bodies of water. Finally, I use the language spoken by an individual as a third measure of exposure. I record dummy variables equal to one if an individual speaks Spanish (or English). This measure of exposure is likely to capture how closely connected an individual is to Spain or Great Britain as well as the amount of media reports of either terrorist attack observed by the respondent. Both language spoken and driving distance provide a measure of exposure to terrorist attacks while allowing the individual to live outside of either Spain or Great Britain.

\section{III.B. Measures of Psychological Characteristics}

I use data from the European Social Survey (ESS) to measure psychological variables. The ESS is a large-scale repeated cross-sectional survey of political and cultural attitudes of individuals in 29 European countries. I use data from five survey waves, centered on the years 2002, 2004, 2006, 2008, and 2010, with anonymized data reported at the personlevel..$^{5}$ I record the log(age), gender, marital status, and education level (harmonized across countries) as control variables. I also record the location of the respondent and the date that the survey was completed. The ESS records a region code for each respondent that typically corresponds to a nomenclature d'unités territoriales statistiques (NUTS) level I, II, or III region code. In some cases, the NUTS level of the region code varies across survey waves. In these cases, I record the most coarse level of aggregation across the survey waves, to provide a consistent regional effect. In a few cases, the region code recorded by ESS does not directly correspond to a NUTS level. In these cases, I match the region code to the closest NUTS region code possible by visual inspection. The ESS also records the exact date

\footnotetext{
${ }^{5}$ The sampling procedure of the ESS is designed to provide a representative sample of the residents of a country, independent of citizenship or language. Minor differences in sampling procedures occurred between countries. Also, sample sizes are roughly equivalent across countries, regardless of total population. To address these issues, I use the weights provided by the ESS to adjust for sampling methods in all of my tests.
} 
of an individual's response to the survey. This allows me to compare responses before and after the 3/11/2004 Madrid attack or the 07/07/2005 London attack, at a daily level.

To provide both predetermined and ex post survey responses, I require that a country participated in the first survey wave in 2002 and at least one of the 2006, 2008, or 2010 surveys. I exclude Israel from the sample because of its long history with terrorism and its geographic separation. This leaves 21 countries in the sample. The large majority of European countries are included, with the one notable exception of Italy, which only participated in the first two rounds of the survey, and thus does not have ex post data available.

The total number of survey responses in the sample is 172,048 ; the number of observations per country is reported in Table I. In untabulated results, the average age of respondents is 46.5 years with a standard deviation of 18.5. Fifty-three percent of respondents are women and $56.5 \%$ of respondents are married. Using the International Standard Classification of Education (ISCED), the highest level of education is lower secondary for $14.3 \%$ of respondents, upper secondary vocational for $16.2 \%$, and upper secondary general for $13.3 \%$. Overall, the sample is a good representation of the diversity of the population in Europe.

To measure trust, I use answers to the question, "Generally speaking, would you say that most people can be trusted, or that you can't be too careful in dealing with people?" This question has been used in other major surveys, including the World Values Survey and the General Social Survey.

Unlike trust, there is no standardized question to measure collectivism and egalitarianism. Therefore, I use questions that reflect the overall idea of these dimensions. To measure collectivism, I use a question that asks whether it is important to help other people and care for their well-being. Egalitarianism is measured by responses to a question that asks whether all people should be treated equally and given equal opportunities.

I measure subjective well-being in two ways. First, I use the question that asks if a longstanding illness, disability, or mental health problem hampers daily activities. Second, I use the question commonly used to measure SWB, "Taking all things together, how happy 
would you say you are?" Krueger and Schkade (2008) shows that this question provides reliable estimates of SWB, as long as sample sizes are not too small. Finally, I measure attitudes consistent with free markets using three questions that ask the respondent to indicate the importance of 1) creativity/originality, 2) being successful, and 3) freedom of choice. The complete questions for all measures are reported in the Online Appendix.

\section{III.C. Summary Statistics of Psychology Variables}

Table I presents averages and standard errors of survey responses for the psychology variables, by country, over the entire sample period from 2002 to 2011. Measured on an 11-point scale from zero to 10 , the average trustfulness across the 21 countries is 4.87 . Denmark scores the highest trust with an average of 6.92 , and Greece scores the lowest with an average of 3.80. Collectivism is measured on a 6-point scale, with the highest response by people in Spain, and the lowest by people in the Czech Republic. Greece scores the highest egalitarianism score and Estonia scores the lowest. Respondents in Spain and Ireland report the fewest long-run health problems, whereas people in Slovenia report the most. The happiest people in the sample are in Denmark (8.33 on a 0/10 scale), the least happy are in Hungary (6.34), and the average is 7.34. Finally, for the attitudes toward free

market ideals, the importance of freedom (4.80 out of 6 ) is higher than the importance of creativity (4.43) and the importance of success (3.69), on average.

At a country-level, there are significant correlations between the psychology variables. In untabulated results, I find a statistically significant correlation of $84.2 \%$ between trustfulness and happiness. Trust and the importance of success are also positively related. Collectivism is negatively related to health problems, but positively correlated with the importance of creativity and freedom, which are also positively correlated with each other. Finally, happiness is positively correlated with the importance of success (41.4\%). There are also intuitive correlations between countries. For example, responses from Finland more closely resemble the responses from Norway and Sweden than responses from Portugal. 


\section{III.D. Empirical Evidence of the Effect of Terrorist Attacks on Psychology}

To give an overall sense of the geography and impact of terrorist attacks on psychology, Figure II presents a map of the European regions in the sample. Darker regions correspond to larger relative declines in happiness from before the 2004 Madrid bombing to afterward. The map shows that across the regions in Spain, people suffered substantial decreases in happiness. The map also reveals that national borders have a strong effect on changes in psychology. While regions in Spain indicate declines in happiness, neighboring regions in Portugal and France do not.

Table II presents the results from the estimation of Equation 1. Each entry reports the difference-in-difference coefficient from a separate regression. First, in Panel A, the London attack led to a positive impact on generalized trust for people residing in Great Britain and for English-speaking people overall, but there is no effect on trust using the travel time to London. Second, the London attacks led to an increase in egalitarian values, using the country dummy and travel time measures of exposure. The attacks also led to a substantial decline in general happiness and the importance of success and an increase in the importance of freedom.

In Panel B, I exclude Great Britain from the analysis to check whether the previous results are influenced by institutional changes in Great Britain following the attack. Using only foreign populations, trust now shows a decline following the attacks and egalitarianism is no longer significant. Second, the effects of the importance of success and freedom are reversed when excluding Great Britain. For people close to London, but outside Great Britain, success is more important and freedom is less important. In addition, there is an indication that the terrorist attacks led to an increase in long-term health problems and less importance of creativity. The contrasting results between Panels A and B are consistent with an institutional influence on cultural values. In particular, the government's response may have led to increases in trust and the importance of equal opportunities. 
Panels $\mathrm{C}$ and D repeat the analysis using the Madrid bombing. Focusing attention on Panel D, which excludes Spain from the analysis, the results show a decrease in trust, consistent with the London attack. Collectivism shows mixed results. Egalitarianism increased for Spanish speaking populations. In addition, long-run health problems increased and general happiness decreased as a result of the Madrid attack, whereas the importance of creativity and freedom both decreased, consistent with the London attack. ${ }^{6}$

The above results could be affected by pre-existing trends in the psychology of Europeans. In particular, time trends in values may be correlated with proximity to London or Madrid, which would cause a spurious relation between the timing of the terrorist attacks and changes in psychology. To address this concern, in Table III, I divide the sample period into four sub-periods: two before the attack and two after. ${ }^{7}$ In the regression results, the earliest sub-period is the omitted baseline period.

The results in Table III are largely consistent with a causal relationship of the attacks on psychology. For the Madrid attack, there is no evidence of a pre-existing trend in the outcome variables. For the London attack, the results on collectivism and egalitarianism indicate a pre-existing trend, and thus can not be directly attributed to the terrorist attack. However, the effects of the attack on trust, happiness, and the importance of creativity and freedom are consistent with a causal interpretation. The presence of pre-existing trends for the London attacks could reflect the earlier response to the Madrid attacks.

Taken together, these results show that terrorist attacks have a meaningful effect on individual psychology. Consistent across both attacks is a decline in happiness and trust, a greater incidence of health problems, and less importance placed on creativity and freedom. The results outside of Great Britain and Spain show that institutions could have meaningful

\footnotetext{
${ }^{6}$ For robustness, I estimate these equations using ordered logit models to account for the ordinal nature of survey responses and find similar results.

7 The first period is from January 2002 to roughly a year prior to the attack, either in London or Madrid. The second pre-attack period covers the year before the attack. The first post-attack period covers the remainder of the attack year and the following year. The second post-attack period covers the rest of the sample period through 2011. For Madrid, I extend the second pre-attack period three months further back in time to create a more even sample size across the four sub-periods.
} 
effects on psychology, which confound the interpretation of the role of psychology in macroeconomic changes. For instance, increased security measures and police presence following terrorist attacks could be the cause for increased trust within Great Britain following the London bombings.

These tests reveal that multiple dimensions of psychology simultaneously change in response to exposure to terrorism. While it would be ideal if only one dimension changed, this is unrealistic in any setting. Even in a controlled experiment, it would be impossible to selectively manipulate just one dimension of psychology, while holding all others constant. Indeed, in cross-region tests, there are multiple strong correlations between the various dimensions, as reported above. This limitation means that though the first set of results shows that psychology changes in response to terrorism, I am not able to draw a specific prediction about the importance of each dimension of psychology for economic activity.

\section{The Impact of Terrorist Attacks on Macroeconomic Activity}

In this part of the paper, I test whether terrorist attacks affect economic activity by studying individuals who are affected by terrorist attacks, but who do not live where the attack occurred. In particular, to measure variation in the exposure to terrorist attacks, I use the fraction of foreign residents who have had a terrorist attack in their home country in the same year, for each region of the countries in my sample. In particular, I estimate the following model:

$$
E_{r, t}=\alpha+\beta A_{r, t}+\sum_{t} \tau_{t} \text { Year }_{t}+\sum_{r} \eta_{r} \text { Region }_{r}+\sum_{r} \delta_{r} \text { Region }_{r} \times Y \text { ear }+\mathbf{X}_{\mathbf{r}, \mathbf{t}} \gamma+\varepsilon_{r, t}
$$

where $A_{r, t}=\sum_{n}$ Attack $_{t, n} \times$ Fraction $_{n, r}$.

$E_{r, t}$ is a measure of economic activity in region $r$ at time $t$, Region $r$ and $Y e a r_{t}$ are a set of location and year fixed effect variables, Region ${ }_{r} \times Y$ ear are region-specific linear time trends, and $\mathbf{X}_{\mathbf{r}, \mathbf{t}}$ is a vector of region-level control variables. The region fixed effects capture 
any time-invariant characteristics that affect economic activity, such as political and legal institutions, natural resources, and predetermined cultural values and beliefs. The regionspecific time trends capture variation in cross-sectional growth rates across the regions.

Attack $_{t, n}$ is an indicator variable for a terrorist attack at time $t$ in nation $n$ and Fraction $_{n, r}$ is the fraction of the population in region $r$ that is a citizen of nation $n$. Therefore, the variable $A_{r, t}$ captures the total fraction of a region's population that is affected by a terrorist attack in a foreign nation. This variable is designed to proxy for temporal changes in a region's psychological condition, orthogonal to possible changes in the region's institutions. Since the separate effect of $A t t a c k_{t, n}$ is equal across all regions, its effect is captured by the year dummies. Likewise, since Fraction $_{n, r}$ is time-invariant, its effect is captured by the region fixed effects.

Data on economic activity are from Eurostat's Regional statistics database from 1995 through 2008, at NUTS II level (roughly one to three million inhabitants). Economic activity is measured using the growth rate of gross domestic product (GDP) and GDP per capita expressed in purchasing power standards (PPS). I also analyze two measures of income: yearly total compensation of employees (measured at the region level in billions of euros) ${ }^{8}$, and yearly total household income (measured at the region level in billions of PPS). Next, I record the gross fixed capital formation (in billions of euro) by region. Finally, I calculate the unemployment rate at the region level as the number of unemployed people divided by the size of the economically-active population. These variables are designed to provide measures of a broad range of economic activity at a detailed sub-national level.

In the first section of the paper, I focused on two large terrorist attacks in Europe. In this section, I broaden my approach to include terrorist attacks from around the world. This provides greater power to identify exposure to terrorism, since there are relatively few terrorist attacks that occur in Europe.

\footnotetext{
${ }^{8}$ This variable is not reported in PPS by Eurostat.
} 
First, to measure the variable of interest, $A_{r, t}$, I require detailed data on the nationality of residents at the region-level. I use data from the Integrated Public Use Microdata Series - International (IPUMS-I). ${ }^{9}$ IPUMS-I collects and harmonizes microdata from national censuses from 62 countries, providing anonymized microdata at the individual level. I collect data from all of the available European countries in IPUMS-I that record both detailed nationality or country of birth and current location of the census respondent at NUTS-level II. ${ }^{10}$ These filters yield the following censuses: Austria (2001), Germany (1987), Greece (2001), Ireland (2002), Italy (2001), Portugal (2001), Romania (2002), Slovenia (2002), and Spain (2001). The microdata are either $5 \%$ or $10 \%$ unweighted samples of the complete census records, which provides a total sample size of 13,267,905 individuals.

IPUMS-I reports nationality and birthplace for 167 countries. For each region, I calculate the percentage of individuals that are citizens of each of these countries (or were born in each country for the Romania census). Across the regions, $94.5 \%$ of the population are citizens of the country where the region is located, on average. The median is $96.6 \%$. To illustrate the level of detail in the data, Table A.1 in the Online Appendix presents an example of citizenship data for NUTS region GR12 Kentriki Makedonia (Central Macedonia) in Greece.

One concern is that most of the census data are not recorded prior to 1995, the start of the economic activity data series. If economic activity leads to demographic changes in the population's citizenship, I could misinterpret the results. For example, if income is low and terrorism is high in Mali, and income is high and terrorism is low in Portugal, then there may be a positive migration from Mali to Portugal. This would lead to an increase in the fraction of Portugal's population affected by terrorism. Thus, I could attribute changes in economic activity to the fraction of the population exposed to terrorism, when in fact the fraction of the population exposed to terrorism is driven by economic activity. By including

\footnotetext{
${ }^{9}$ Minnesota Population Center. Integrated Public Use Microdata Series, International: Version 6.1 [Machinereadable database]. Minneapolis: University of Minnesota, 2011. Original data are from the national statistical offices of Austria, Germany, Greece, Ireland, Italy, Portugal, Slovenia, Spain, and Romania.

${ }^{10}$ Germany only records NUTS region level I, but it is included as well. A number of countries with microdata on IPUMS-I have to be excluded due to missing data, including France and the UK.
} 
region-specific time trends, I account for any long-run changes in demographics. In addition, I test for changes in migration in later robustness tests. Second, one may be concerned that the variation in the diversity of national origin across regions may drive my results. However, the region fixed effects account for the majority of the impact of diversity, since diversity does not change rapidly over time.

Next, I expand the data to include terrorist attacks around the world, using data from the Global Terrorism Database (GTD). This database contains data on almost 100,000 terrorist attacks from 1970 to 2010 and is the most complete source of data on terrorist attacks currently available. Because the definition of a terrorist attack is debatable, the GTD has established the following criteria for a terrorist act to be included in the database: the act must be intentional, the act must entail violence or threat of violence, and the perpetrators must be sub-national actors. In addition, I only include attacks in my sample that meet the three following additional criteria as specified in the GTD guidebook: 1) the act must be aimed at attaining a political, economic, religious, or social goal; 2) there must be evidence that the act had an intention to coerce, intimidate, or convey some other message to a larger audience than the immediate victims; and 3) the act must be outside the context of legitimate warfare activities. Finally, I only include incidents where at least one person was killed. This leaves a sample of 12,118 terrorist attacks from 1995 to 2008. Combining all these data and omitting observations with missing data leads to a sample of 1,270 region-year observations in 91 different European regions.

When quantifying the psychological impact of these attacks, it is important to account for the ways in which people cope with violence. Becker and Rubinstein (2011) argue that people rationally overcome fear. They show that during the Al Aqsa Intifada in Israel, where buses were often targeted by terrorists, regular bus riders didn't reduce their usage of buses as much as irregular bus riders. Second, research in psychology provides a theory of resilience to trauma, where people overcome the negative psychological impacts of traumatic episodes (Fredrickson, Tugade, Waugh, and Larkin, 2003; Bonanno, 2004). 
These theories suggest that the impact of terrorist attacks depends upon the expectations of violence that have been formed from past experience. Therefore, to measure unexpected terrorist attacks, I construct a dummy variable equal to one if the total number of people killed in terrorist attacks in country $n$ in year $t$ is greater than the median number of people killed in the country over years $t-5$ to $t-1$. I normalize the number of fatalities by the country population, but since the variable is formed by a within-country comparison, it makes little difference. Thus, this variable captures abnormally high levels of terrorist attacks, using a measure of country-specific expected violence.

If there is only one fatality in a terrorist attack, it may not have a strong effect on a nation's psychology. Therefore, I also calculate two analogous measures, using only attacks with at least 50 or 100 fatalities. I compute these measures as before, comparing the number of fatalities in a given year to the median of the previous five years, but I restrict the sample to only include attacks with at least 50 or 100 fatalities. Compared to the 12,118 attacks with at least one fatality, there are 175 attacks with at least 50 fatalities, and 58 attacks with at least 100 fatalities. Thus, the rarity of such severe attacks makes them more likely to have larger psychological impacts.

\section{IV.A. Summary Statistics of Global Terrorism Incidents and Regional Economics}

Figure III presents the time series of abnormal terrorism from 1995 to 2008, using attacks with at least one fatality. Of a total of 170 countries represented in the GTD, 32 experienced unusually high levels of terrorist fatalities in 1995, rising to a peak in 1997 with 52 countries, and falling to a minimum of 12 countries the following year. Normalizing the counts of terrorism by the numbers of countries in each region shows that countries in the Middle East experienced the largest number of years with abnormal violence, with $23.8 \%$ of countries experiencing abnormal violence in an average year. This is followed by Asia with 20.0\%, Africa with $18.0 \%$, the Americas with $11.4 \%$, and Oceania with $2.4 \%$. 
Figure III does not reveal a clear time pattern in the the global incidence of terrorism. However, there do appear to be waves of terrorism where multiple countries around the globe experience greater levels of violence concurrently. Indeed, in untabulated tests, the time series of abnormal terrorism for countries in Africa, the Americas, Asia, and Europe are positively and significantly correlated.

These data reveal that the location and timing of terrorist attacks exhibit wide variation. This is important for my identification strategy because it means that the population of European residents affected by terrorism in their home countries is not dominated by people from one particular world region, but rather, all populations of foreigners in Europe are likely to be affected by terrorism in any given year. In addition, the year effects in the empirical model captures the time-series variation in worldwide waves.

Summary statistics of the terrorist attack and economic activity variables are presented in Table IV. First, $0.70 \%$ of the population is affected by terrorist attacks abroad, on average, across the 1,270 region-year observations. Using the less common, but more severe attacks which killed at least 50 or 100 people, the average fraction of population affected is $0.08 \%$ and $0.04 \%$. There is significant variation across these measures, compared to their means, with standard deviations of $1.200 \%, 0.165 \%$ and $0.126 \%$. I also calculate a dummy variable for local terrorist attacks in the 91 European regions. Across all region-years, $16.1 \%$ experienced a terrorist attack with at least one fatality. I do not calculate a dummy based on more severe attacks because they are very rare in Europe during this time period.

It is important to acknowledge that the fractions of the total population affected by terrorism abroad are small. This means that the absolute level of the effect of terrorism on the region's economic activity is expected to be small as well. This does not invalidate the approach, and if anything, makes finding any significant results less likely.

Panel B of Table IV presents summary statistics for the economic activity variables. GDP per capita, measured in PPS, is 19,481 on average, with a median of 19,250. GDP growth is roughly $4.9 \%$ on average and $4.8 \%$ at the median and the unemployment rate is $8.4 \%$, on 
average. Compensation at the region-level is about 23.7 billion euros and income is about 37 billion euros, on average. Investment in fixed capital is roughly 10.5 billion euros in an average region-year. Finally, the population of an average region is 2.5 million people.

\section{IV.B. Empirical Evidence of the Effects of Foreign Terrorism on Macroeconomic Activity}

Table V presents estimates of Equation 2. In Panel A, I first verify that local terrorist attacks have an effect on economic activity, following prior research. Regressions results using just region fixed effects and results using region fixed effects plus region-specific trends are reported. Consistent with prior literature (Eckstein and Tsiddon, 2004; Blomberg, Hess, and Orphanides, 2004), I find that the occurrence of a terrorist attack in one of the 91 European regions leads to a significant decline in GDP per capita and GDP growth. GDP per capita falls by 148 PPS units, or about $0.7 \%$ of the regional average. GDP growth falls by a larger amount, $1.1 \%$ compared to the average of $4.9 \%$. At the same time, I find that compensation of employees increases and the unemployment rate falls. These results are consistent with the theory presented in Eckstein and Tsiddon (2004), where the overall output falls, but government spending increases.

I next estimate the effect of terrorism, excluding local terrorist attacks to control for possible endogenous institutional changes. Since attacks are foreign, I use the most severe measure of terrorist attacks, calculating the dummy variable for terrorism by only including attacks where at least 100 people were killed. I find that foreign terrorist attacks have a strikingly different impact on economic outcomes. In contrast to the local effects of terrorism, I find that GDP per capita and GDP growth both increase when a larger fraction of the foreign population is affected by terrorism. The regression estimates imply that if $1 \%$ of the population were affected by terrorism, GDP per capita would rise by 250 PPS units, or $1.3 \%$

of the average GDP, and GDP growth would increase. Aggregate household income rises by 727 million, or $2.0 \%$ of the average, when $1 \%$ of the population is affected by terrorist attacks. Compensation of employees and gross fixed capital formation both rise, but they 
are insignificant once region-specific time trends are included. Finally, unemployment rates are unaffected. The results presented here are large and meaningful, though I place more weight on the sign of the effect, than on the exact magnitude, given that the fraction of the population affected is small.

These results provide causal evidence that terrorism aboard affects economic activity. Because the research design controls for institutional changes, psychological changes are the most likely cause. This means that psychological traits, such as cultural values, subjective well being, and attitudes towards capitalism, have direct effects on economic outcomes. These results also highlight the difference between the psychological and non-psychological effects of terrorism on economic activity. In particular, the non-psychological effects, including governmental responses, lead to negative outcomes, consistent with Eckstein and Tsiddon (2004). In contrast, the psychological effects lead to positive outcomes. After next presenting additional robustness tests, I discuss potential explanations for these positive outcomes in more detail.

\section{IV.C. Robustness Tests}

As argued above, because I use foreign terrorist attacks, it is unlikely that my main results are explained by reverse causation. I next empirically test this argument. First, in Panel A of Table VI, I include one-year leads and lags of the treatment variable in tests on local terrorist attacks, where reverse causation is more likely. I find that economic outcome variables are significantly related to future local terrorist attacks. These results show that endogeneity confounds the interpretation of the effects of terrorist attacks on local economic outcomes.

In Panel B, I perform the same analysis, but exclude local terrorist attacks. For all economic activity variables, the leading term is highly insignificant, while the current or lagged terrorism variable is significant for GDP per capita, GDP growth, household income, and unemployment rate. These results show that economic outcomes do not determine the fraction of those exposed to foreign attacks and reverse causation does not explain the 
results. These results also indicate that the results are temporary, only impacting economic outcomes in the same year as the foreign attacks. This may reflect that people quickly revert to the status quo, especially when the traumatic episode is distant.

A second potential concern with the main results is that though I include region-level fixed effects, the fraction of foreigners affected by terrorist attacks may proxy for some other region-level variable. To provide further evidence that the effects I document are directly related to terrorist attacks, I provide estimates using variation in the number of fatalities caused by terrorism. Even if terrorist attacks do not occur randomly across countries, the number of fatalities is more likely to be a random outcome. Since attacks with greater numbers of fatalities are likely to have a bigger effect on psychology, this provides additional exogenous variation in the effect of terrorism on economic outcomes.

The coefficient estimates reported in Table A.2 in the Online Appendix, provide evidence that the exposure to terrorism variable is directly related to terrorist attacks. Comparing the results of these tests to the main results in Table V, I find that greater fatalities leads to larger effects. The point estimate of the impact of exposure to terrorism on household income is 0.727 when there are at least 100 fatalities in the main results, 0.544 when there are at least 50 fatalities, and an insignificant -0.042 when there is at least one fatality. There is a similar pattern for GDP growth and GDP per capita.

Next, I run tests to account for the possibility of institutional spillover. If institutional responses spread from one country to another, they are more likely to spread to countries that are geographically close. To account for this possibility, I run identical tests as in Table V and Table VI but only include attacks that are in distant countries. ${ }^{11}$ These results are qualitatively unchanged from the main results.

\footnotetext{
${ }^{11}$ Distance is measured using data from Centre d'Etudes Prospectives et d'Informations Internationales (CEPII). Distant countries are those that are greater than 3,363 kilometers away, the distance between Portugal and Finland, which is the greatest distance between any two countries in the European Union in 2001.
} 
Finally, I test whether terrorist attacks lead to migration to European countries. Yearly data on a region's population by country-of-origin is unavailable, so I use yearly nation-level data on population demographics from Eurostat. I record population data for country-pair years, where pairs are formed by a European host country and a worldwide country of origin. I run lagged dependent variable fixed effects GMM regressions, as in Arellano and Bond (1991), where the dependent variable is the logged population of each country-pair and the fixed effects are at the country-pair level. I also include host country-specific time trends and year effects. The key explanatory variable is the lagged incidence of abnormal terrorist attacks in the origin country. I find no effect on immigration to Europe following attacks, using attack dummies based on the occurrence of at least one fatality, more than 50, and more than 100 fatalities, and also including an interaction with geographic distance to account for the difficulty of immigration. These results indicate that the effects on macroeconomic outcomes are not driven by changes in demographics induced by foreign terrorist attacks. Table A.3 in the Online Appendix reports these results.

\section{Psychological Mechanisms on Macroeconomic Outcomes}

The results presented above are provocative. They suggest that exposure to foreign terrorist attacks has a positive effect on important macroeconomic outcomes. In this section, I present arguments and empirical evidence to try to better understand how exposure to terrorism can lead to these outcomes.

Prior research provides possible explanations for the increase in output and income. In particular, psychology studies find that a decrease in positive affect makes people less patient (Ifcher and Zarghamee, 2011) and more reciprocal in experimental gift exchanges (Kirchsteiger, Rigotti, and Rustichini, 2006). A number of psychology studies argue that though trauma has serious negative consequences, it also has the potential for offsetting positive cognitive processes, such as positive changes in the quality of interpersonal relationships and 
self-determination (Tedeschi and Calhoun, 2004; Fredrickson, Tugade, Waugh, and Larkin, 2003; Bonanno, 2004).

Economics research finds similar results. Voors et al. (2012) find that exposure to political and military conflict leads to greater risk-seeking behavior and less patience. Blattman (2009) finds that greater exposure to violence in Uganda led to greater civic participation and community leadership. Bellows and Miguel (2009) shows that exposure to violence in Sierra Leone led to greater community activism, but finds no long-run effect on socioeconomic status, consistent with the temporary effects I find. Bauer, Cassar, Chytilová, and Henrich (2014) runs experiments in Georgia and Sierra Leone and find that exposure to violence led people to become more egalitarian and more willing to share, consistent with greater community activism. Finally, Gilligan, Pasquale, and Samii (2011) shows that in experiments in Nepal, greater exposure to violence leads to greater community activism.

These papers' results provide a consistent theme. Though exposure to violence has negative effects on well-being, people respond by increasing social capital. Though the effect of social capital on macroeconomic outcomes is debatable (see Sobel (2002) for a discussion), this is one potential mechanism through which terrorism affects economic outcomes. More broadly, this also implies that the importance of terrorism is traced to changes in one's views towards others, manifested as community involvement, rather than views towards one's self, such as well-being. I next present tests to try to better understand this dichotomy.

\section{V.A. Empirical Evidence of the Effect of Natural and Technological Disasters}

In this section of the paper, I compare terrorist attacks to other traumatic episodes. Natural and technological disasters, such as earthquakes and factory explosions, share many similarities with terrorist attacks. Both terrorist attacks and disasters involve a traumatic and unexpected loss of life, both lead to government responses, and both have psychological impacts (Galea, Nandi, and Vlahov, 2005). However, one key difference is that terrorist attacks are purposeful destruction committed by others, whereas disasters are not. This 
difference is likely to affect the psychological impact of terrorism and disasters. In particular, since terrorist attacks are intentional destruction, it is reasonable that people affected by terrorism may change their attitudes towards other people and their beliefs about human nature. In contrast, people affected by accidental or natural disasters are less likely to change their views about other people in the same way.

I collect data on natural and technological disasters from the EM-DAT International Disaster Database, maintained by the World Health Organization (WHO) and the Centre for Research on the Epidemiology of Disasters (CRED). The database collects information on over 18,000 mass disasters from 1900 to the present. For a disaster to be recorded in the database, at least one of the following criteria must be met: 1) at least ten fatalities are reported; 2) at least 100 people are affected; 3) there is a declaration of a state of emergency; or 4) there is a call for international assistance. The data include the number of fatalities, the location, date, and a classification of disasters by type. ${ }^{12}$

Compared to terrorist attacks, natural disasters are much deadlier. From 1995 to 2010, there were 85,900 fatalities from natural disasters in an average year, compared to 5,278 fatalities from terrorist attacks. Technological accidents are also more deadly than terrorist attacks, with 9,068 fatalities in an average year. These comparisons hold if I only include data of the deadliest incidents, with at least 100 fatalities. Thus, based solely on the average destructive outcome of natural and technological disasters and terrorist attacks, I expect that natural disasters will have greater effects on economic outcomes.

Using worldwide natural and technological accidents, I calculate the exposure to disasters in the home country of foreign residents in Europe, analogous to the measure of exposure to terrorism. As before, I control for within-country norms of fatalities in the prior five years. Using these variables, I estimate the same empirical model as before, but include all three

\footnotetext{
${ }^{12}$ Natural disasters include earthquakes, volcanic eruptions, avalanches, landslides, storms, floods, extreme temperatures, droughts, wildfires, health epidemics, and insect infestations. Technological disasters include industrial accidents such as chemical spills or factory explosions and transportation accidents such as plane crashes or train accidents.
} 
variables for terrorism and disasters in the same model. This is important because terrorist attacks often follow natural disasters. Similar to evidence in Cavallo, Galiani, Noy, and Pantano (2013), in unreported tests I find that the likelihood that a region-year experiences a terrorist attack is positively related to the occurrence of a natural disaster in the same year and in the prior year. The opposite relation does not hold, which verifies that the natural disasters identified in the data are truly random.

Table VII shows that the local effects of natural disasters include a decrease in GDP growth and unemployment rates and an increase in compensation, income, and investment. Technology disasters are associated with increases in GDP per capita, income, and investment, and decreases in GDP growth and the unemployment rate. The effects of terrorist attacks are unchanged from the prior results.

As with terrorist attacks, endogeneity makes interpreting the coefficient estimates for technology disasters difficult. Technology disasters may occur more frequently in wealthier regions, consistent with a positive relationship between GDP per capita, household income, and the occurrence of a technology disaster, such as a plane crash or factory explosion. In addition, the government response to the disaster will also confound the local effects of disasters on economic outcomes.

In Panel B, I use the impact of disasters on foreign populations to overcome these endogeneity problems. First, the impact of terrorism remains the same as in prior results. GDP per capita, GDP growth, and household income all rise, with point-estimates nearly identical to the main results. The estimates for exposure to natural disasters have a similar effect as terrorist attacks, though with a smaller magnitude of impact. GDP per capita, GDP growth, and household income all rise, while the unemployment rate falls. Compared to an increase of 268 PPS units of GDP per capita when $1 \%$ of the population is affected by terrorist attacks, natural disasters only lead to an increase of 56 PPS units. Similarly, the effect on GDP growth for terrorism is $2.7 \%$ and household income is 738 million PPS, 
compared to $0.3 \%$ and 121 million for natural disasters. Each of these differences is statistically significant at conventional levels. In contrast, technology disasters have no effect on the outcome variables except a small positive effect on employee compensation.

These results are interesting for a number of reasons. First, though natural disasters kill 16 times as many people as terrorist attacks in an average year, their impact on economic outcomes via foreigners living abroad is estimated to be roughly one-fifth the magnitude of terrorist attacks. In addition, terrorist attacks have stronger impacts than technological disasters which are similar to terrorist attacks in many ways. These results suggest that the psychological impact of terrorist attacks is greater than the impact of the much deadlier natural and technological disasters.

Second, these results shed some light on which dimensions of psychology affect economic outcomes. Compared to disasters, terrorist attacks are more likely to affect psychological views towards others, such as trust and collectivism, than they are to affect views towards one's self, such as subjective well-being. Because terrorist attacks have a larger impact than disasters, we can infer that views towards others are more important for economic activity, than views towards one's self. This is consistent, for example, with the role of trust as a facilitator of trade (Arrow, 1972) and the importance of social interaction for economic activity (Manski, 2000).

\section{ConClusion}

This paper provides new evidence on the effect of terrorism on individual psychology and macroeconomic activity, controlling for reverse causation and the endogenous response of institutions to terrorism. First, I find that terrorist attacks have substantial impacts on multiple dimensions of psychology. Controlling for demographics and sub-national region fixed effects, I find that trust, subjective well-being, and the importance of creativity and freedom significantly decline following the 2004 Madrid train bombings and the 2005 London 
metro terrorist attacks. Second, I find that local terrorist attacks have a negative impact on GDP and income. However, exposure to foreign attacks has a positive impact on GDP and income. The results are robust to tests of migration and institutional spillover effects.

These results are most consistent with a psychological influence on macroeconomic results. Though the positive effect of terrorism on macroeconomic outcomes is counter-intuitive, it is consistent with a wide range of recent papers showing that exposure to violence and trauma leads to increases in social capital. To better understand which psychological characteristics drive economic activity, I compare terrorist attacks to natural and technological disasters. I find that terrorist attacks have much larger effects than either natural or technological disasters, even though terrorist attacks involve a smaller loss of life. This result suggests that psychological attitudes towards others, such as trust, are more important for economic outcomes than attitudes towards one's self, such as subjective well-being.

Psychological effects are ubiquitous in our daily lives, but often ignored when studying the aggregate consequences of economic decision-making. In his 2007 Presidential Address, George Akerlof argues that accounting for social norms and customs is important for understanding macroeconomic activity. The results in this paper validate Akerlof's assertion and suggest that changes in psychology cause meaningful changes in important economic outcomes. 


\section{REFERENCES}

Abadie, Alberto, "Poverty, Political Freedom, and the Roots of Terrorism," American Economic Review, 96 (2006), 50-56.

— , and Javie Gardeazabal, "The Economic Costs of Conflict: A Case Study of the Basque Country," American Economic Review, 93 (2003), 113-132.

Aghion, Philippe, Alberto Alesina, and Francesco Trebbi, "Endogenous Political Institutions," Quarterly Journal of Economics, 119 (2004), 565-611.

Ahern, Jennifer, Sandro Galea, Heidi Resnick, Dean Kilpatrick, Michael Bucuvalas, Joel Gold, and David Vlahov, "Television Images and Psychological Symptoms after the September 11 Terrorist Attacks," Psychiatry, 65 (2002), 289-300.

Ahern, Kenneth R., Daniele Daminelli, and Cesare Fracassi, "Lost in Translation? The effect of cultural values on mergers around the world," Journal of Financial Economics,, 117 (2015), 165-189.

Akerlof, George A., "The Missing Motivation in Macroeconomics," American Economic Review, 97 (2007), 5-36.

Algan, Yann, and Pierre Cahuc, "Inherited Trust and Growth," American Economic Review, 100 (2010), 2060-2092.

Arellano, Manuel, and Stephen Bond, "Some Tests of Specification for Panel Data: Monte Carlo Evidence and an Application to Employment Equations," Review of Economic Studies, 58 (1991), 277-297.

Arrow, Kenneth J., "Gifts and Exchanges," Philosophy and Public Affairs, 1 (1972), 343-362.

Barro, Robert J., and Rachel M. McCleary, "Religion and Economic Growth across Countries," American Sociological Review, 68 (2003), 760-781.

Bartling, Björn, Ernst Fehr, Michel André Maréchal, and Daniel Schunk, "Egalitarianism and Competitiveness," American Economic Review: Papers \& Proceedings, 99 (2009), 93-98. 
Bauer, Michal, Alessandra Cassar, Julie Chytilová, and Joseph Henrich, "Wars Enduring Effects on the Development of Egalitarian Motivations and In-Group Biases," Psychological Science, 25 (2014), 47-57.

Becker, Gary S., and Yona Rubinstein, "Fear and the Response to Terrorism: An Economic Analysis," University of Chicago and Brown University Working Paper, (2011).

Bellows, John, and Edward Miguel, "War and Local Collective Action in Sierra Leone," Journal of Public Economics, 93 (2009), 1144-1157.

Blattman, Christopher, "From Violence to Voting: War and Political Participation in Uganda," American Political Science Review, 103 (2009), 231-247.

Blomberg, S. Brock, and Gregory D. Hess, "How Much Does Violence Tax Trade?," The Review of Economics and Statistics, 88 (2006), 599-612.

— , and Athanasios Orphanides, "The Macroeconomic Consequences of Terrorism," Journal of Monetary Economics, 51 (2004), 1007-1032.

Blunk, Scott S., David E. Clark, and James M. McGibany, "Evaluating the long-run impacts of the 9/11 terrorist attacks on US domestic airline travel," Applied Economics, 38 (2006), $363-370$.

Bonanno, George A., "Loss, Trauma, and Human Resilience: Have We Underestimated the Human Capacity to Thrive After Extremely Aversive Events?," American Psychologist, 59 (2004), 20-29.

— , and John T. Jost, "Conservative Shift Among High-Exposure Survivors of the September 11th Terrorist Attacks," Basic and Applied Social Psychology, 28 (2006), 311323.

Brett, Jeanne M., "Culture and Negotiation," International Journal of Psychology, 35 (2000), $97-104$.

Brück, Tilman, Fernanda Llussá, and José A. Tavares, "Entrepreneurship: The Role of Extreme Events," European Journal of Political Economy, 27 (2011), S78-S88. 
Bux, Shahid M., and Sarah M. Coyne, "The Effects of Terrorism: The Aftermath of the London Terror Attacks," Journal of Applied Social Psychology, 39 (2009), 2936-2966.

Carmen, Elaine H., Patricia P. Rieker, and Trudy Mills, "Victims of Violence and Psychiatric Illness," The American Journal of Psychiatry, 141 (1984), 378-383.

Cavallo, Eduardo, Sebastian Galiani, Ilan Noy, and Juan Pantano, "Catastrophic Natural Disasters and Economic Growth," Review of Economics and Statistics, 95 (2013), 15491561.

Collimore, Kelsey C., Randi E. McCabe, R. Nicholas Carleton, and Gordon J.G. Asmundson, "Media exposure and dimensions of anxiety sensitivity: Differential associations with PTSD symptom clusters," Journal of Anxiety Disorders, 22 (2008), 1021-1028.

Di Tella, Rafael, Sebastian Galiani, and Ernesto Schargrodsky, "The Formation of Beliefs: Evidence from the Allocation of Land Titles to Squatters," Quarterly Journal of Economics, 122 (2007), 209-241.

Di Tella, Rafael, and Robert MacCulloch, "Some Uses of Happiness Data in Economics," Journal of Economic Perspectives, 20 (2006), 25-46.

Di Tella, Rafael, Robert J. MacCulloch, and Andrew J. Oswald, "Preferences over Inflation and Unemployment: Evidence from Surveys of Happiness," American Economic Review, 91 (2001), 335-341.

— , "The Macroeconomics of Happiness," Review of Economics and Statistics, 85 (2003), 809-827.

Di Tella, Rafael, and Ernesto Schargrodsky, "Do Police Reduce Crime? Estimates Using the Allocation of Police Forces After a Terrorist Attack," American Economic Review, 94 (2004), 115-133.

Dolan, Paul, Tessa Peasgood, and Mathew White, "Do we really know what makes us happy? A review of the economic literature on the factors associated with subjective well-being," Journal of Economic Psychology, 29 (2008), 94-122. 
Draca, Mirko, Stephen Machin, and Robert Witt, "Panic on the Streets of London: Police, Crime, and the July 2005 Terror Attacks," American Economic Review, 101 (2011), 21572181.

Easterlin, Richard A., "Does Economic Growth Improve the Human Lot? Some Empirical Evidence," in Nations and Households in Economic Growth: Essays in Honor of Moses Abramowitz, Paul A. David and Melvin W. Reder, eds. (Academic Press, 1974).

Eckstein, Zvi, and Daniel Tsiddon, "Macroeconomic Consequences of Terror: Theory and the case of Israel," Journal of Monetary Economics, 51 (2004), 971-1002.

Fiske, Alan P., Structures of Social Life: The Four Elementary Forms of Human Relations (New York: Free Press (Macmillan), 1991).

Fredrickson, Barbara L., Michele M. Tugade, Christian F. Waugh, and Gregory R. Larkin, "What Good Are Positive Emotions in Crises? A Prospective Study of Resilience and Emotions Following the Terrorist Attacks on the United States on September 11th, 2001," Journal of Personal and Social Psychology, 84 (2003), 365-376.

Frey, Bruno S., Simon Luechinger, and Alois Stutzer, "The life satisfaction approach to valuing public goods: The case of terrorism," Public Choice, 138 (2009), 317-345.

Gabriel, Rafael, Laura Ferrando, Enrique Sainz Cortón, Carlos Mingote, Eduardo GarcíaCamba, Alberto Fernández Liria, and Sandro Galea, "Psychopathological consequences after a terrorist attack: An epidemiological study among victims, the general population, and police officers," European Psychiatry, 22 (2007), 339-346.

Galea, Sandro, Jennifer Ahern, Heidi Resnick, Dean Kilpatrick, Michael Bucuvalas, Joel Gold, and David Vlahov, "Psychological Sequelae of the September 11 Terrorist Attacks in New York City," New England Journal of Medicine, 346 (2002), 982-987.

Galea, Sandro, Arijit Nandi, and David Vlahov, "The Epidemiology of Post-Traumatic Stress Disorder after Disasters," Epidemiologic Reviews, 27 (2005), 78-91.

Gassebner, Martin, Richard Jong-A-Pin, and Jochen O. Mierau, "Terrorism and Electoral Accountability: One Strike, You're Out!," Economics Letters, 100 (2008), 126-129. 
Gassebner, Martin, and Simon Luechinger, "Lock, stock, and barrel: A comprehensive assessment of the determinants of terror," Public Choice, 149 (2011), 235-261.

Gilligan, Michael J., Benjamin J. Pasquale, and Cyrus D. Samii, "Civil War and Social Capital: Behavioral-Game Evidence from Nepal," New York University Working Paper, (2011).

Gorodnichenko, Yuriy, and Gerard Roland, "Culture, Institutions, and the Wealth of Nations," Review of Economics and Statistics, 99 (2017), 402-416.

Gould, Eric D., and Esteban F. Klor, "Does Terrorism Work?," Quarterly Journal of Economics, 125 (2010), 1459-1510.

Gould, Eric D., and Guy Stecklov, "Terror and the Costs of Crime," Journal of Public Economics, 93 (2009), 1175-1188.

Guiso, Luigi, Paola Sapienza, and Luigi Zingales, "Does Culture Affect Economic Outcomes?," The Journal of Economic Perspectives, 20 (2006), 23-48.

— , "Cultural Biases in Economic Exchange?," Quarterly Journal of Economics, 124 (2009), 1095-1131.

Hamilos, Paul, "After four-month court case, Spain is braced for verdicts in train bombings that killed 191," The Guardian, October 31 (2007), 16.

Hofstede, Geert, Culture's Consequences: International Differences in Work-Related Values (Beverly Hills, CA: Sage Publications, Inc., 1980).

— , Culture's Consequences: Comparing Values, Behaviors, Institutions, and Organizations Across Nations, Second ed (Thousand Oaks, CA: Sage Publications, 2001).

Ifcher, John, and Homa Zarghamee, "Happiness and Time Preference: The Effect of Positive Affect in a Random-Assignment Experiment," American Economic Review, 101 (2011), 3109-3129.

Kahneman, Daniel, and Richard Thaler, "Economic Analysis and the Psychology of Utility: Applications to Compensation Policy," American Economic Review, 81 (1991), 341-346. 
Kahneman, Daniel, Peter Wakker, and Rakesh Sarin, "Back to Bentham? Explorations of Experienced Utility," Quarterly Journal of Economics, 112 (1997), 375-406.

Kirchsteiger, Georg, Luca Rigotti, and Aldo Rustichini, "Your Morals Might Be Your Moods," Journal of Economic Behavior \& Organization, 59 (2006), 155-172.

Knack, Stephen, and Philip Keefer, "Does Social Capital Have an Economic Payoff? A Cross-Country Investigation," Quarterly Journal of Economics, 112 (1997), 1251-1288.

Krueger, Alan B., and David D. Laitin, "in Kto Kogo?: A Cross-Country Study of the Origins and Targets of Terrorism, Philip Keefer and Norman Loayza, eds. (Cambridge University Press, 2008).

Krueger, Alan B., and David A. Schkade, "The reliability of subjective well-being measures," Journal of Public Economics, 92 (2008), 1833-1845.

Llussá, Fernanda, and José Tavares, "Which Terror at Which Cost? On the Economic Consequences of Terrorist Attacks," Economics Letters, 110 (2011), 52-55.

Manski, Charles F., "Economic Analysis of Social Interactions," Journal of Economic Perspectives, 114 (2000), 115-136.

Margolin, Gayla, and Elana B. Gordis, "The Effects of Family and Community Violence on Children," Annual Review of Psychology, 51 (2000), 445-479.

Montalvo, José G., "Voting After the Bombings: A Natural Experiment on the Effect of Terrorist Attacks on Democratic Elections," Review of Economics and Statistics, 93 (2011), $1146-1154$.

Muñoz, Manuel, María Crespo, Eloísa Pérez-Santos, and José Juan Vázquez, "We Were All Wounded on March 11 in Madrid: Immediate Psychological Effects and Interventions," European Psychologist, 9 (2004), 278-280.

Murphy, Edward F., John D. Gordon, and Aleta Mullen, "A Preliminary Study Exploring the Value Changes Taking Place in the United States since the September 11, 2001 Terrorist Attack on the World Trade Center in New York," Journal of Business Ethics, 50 (2004), $81-96$. 
National Consortium for the Study of Terrorism and Responses to Terrorism, 2011, "Global Terrorism Database [Data file]," Retrieved from http://www.start.umd.edu/gtd.

Rubin, G. James, Chris R. Brewin, Neil Greenberg, John Simpson, and Simon Wessely, "Psychological and behavioural reactions to the bombings in London on 7 July 2005: Cross sectional survey of a representative sample of Londoners," British Medical Journal, $331(2005), 1-7$.

Schlenger, William E., Juesta M. Caddell, Lori Ebert, B. Kathleen Jordan, Kathryn M. Rourke, David Wilson, Lisa Thalji, J. Michael Dennis, John A. Fairbank, and Richard A. Kulka, "Psychological Reactions to Terrorist Attacks: Findings From the National Study of Americans' Reactions to September 11," Journal of the American Medical Association, 288 (2002), 581-588.

Schuster, Mark A., Bradley D. Stein, Lisa H. Jaycox, Rebecca L. Collins, Grant N. Marshall, Marc N. Elliott, Annie J. Zhou, David E. Kanouse, Janina L. Morrison, and Sandra H. Berry, "A National Survey of Stress Reactions After the September 11, 2001 Terrorist Attacks," New England Journal of Medicine, 345 (2001), 1507-1512.

Schwartz, Shalom, "Beyond individualism/collectivism: New cultural dimensions of values," in Individualism and Collectivism: Theory, Method and Applications., U. Kim H. C. Triandis C. Kagitcibasi S. C. Choi and G. Yoon, eds. (Newbury Park, CA: Sage Publications, Inc., 1994).

Seo, Dong-Chul, and Mohammad R. Torabi, "National Study of Emotional and Perceptional Changes Since September 11," American Journal of Health Education, 35 (2004), 37-45. Siegel, Jordan I., Amir N. Licht, and Shalom H. Schwartz, "Egalitarianism and International Investment," Journal of Financial Economics, 102 (2011), 621-642.

Smith, Tom W., Kenneth A. Rasinski, and Marianna Toce, "America Rebounds: A National Study of Public Response to the September 11th Terrorist Attacks," NORC Working Paper, (2001). 
Sobel, Joel, "Can We Trust Social Capital?," Journal of Economic Literature, 40 (2002), 139-154.

Speckhard, Anne, "Acute Stress Disorder in Diplomats, Military, and Civilian Americans Living Abroad Following the September 11 Terrorist Attacks on America," Professional Psychology: Research and Practice, 34 (2003), 151-158.

Spolaore, Enrico, and Romain Wacziarg, "The Diffusion of Development," The Quarterly Journal of Economics, 124 (2009), 469-529.

Stevenson, Betsey, and Justin Wolfers, "Economic Growth and Subjective Well-Being: Reassessing the Easterlin Paradox," Brookings Papers on Economic Activity, (2008), 1-87.

Tabellini, Guido, "The Scope of Cooperation: Values and Incentives," The Quarterly Journal of Economics, 123 (2008), 905-950.

— , "Culture and Institutions: Economic Development in the Regions of Europe," Journal of the European Economic Association, 8 (2010), 677-716.

Tavares, José, "The Open Society Addresses Its Enemies: Shocks, Disasters, and Terrorist Attacks," Journal of Monetary Economics, 51 (2004), 1039-1070.

Tedeschi, Richard F., and Lawrence G. Calhoun, "Posttraumatic Growth: Conceptual Foundations and Empirical Evidence," Psychological Inquiry, 15 (2004), 1-18.

Trompenaars, Fons, Riding the Wave of Culture (London: The Economist Books, 1993).

Voors, Maarten J., Eleonora E. M. Nillesen, Philip Verwimp, Erwin H. Bulte, Robert Lensink, and Daan P. Van Soest, "Violent Conflict and Behavior: A Field Experiment in Burundi," American Economic Review, 102 (2012), 941-964.

Zak, Paul J., and Stephen Knack, "Trust and Growth," Economic Journal, 111 (2001), $295-321$. 


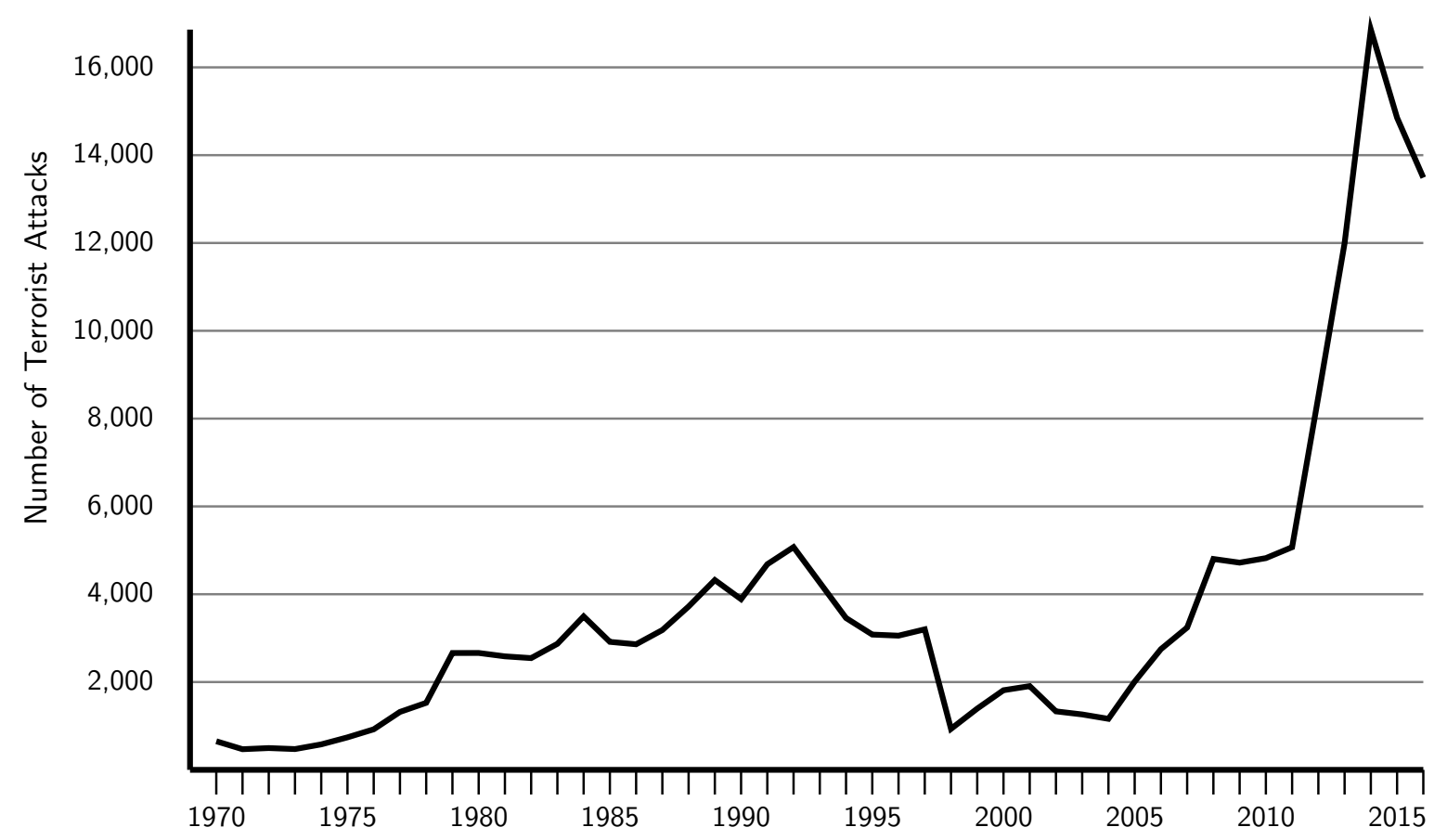

Figure I

Terrorist Attacks Across the World from 1970 to 2016

Data are from the Global Terrorism Database (GTD). A terrorist attack is defined by GTD as "the threatened or actual use of illegal force and violence by a non-state actor to attain a political, economic, religious, or social goal through fear, coercion, or intimidation." 


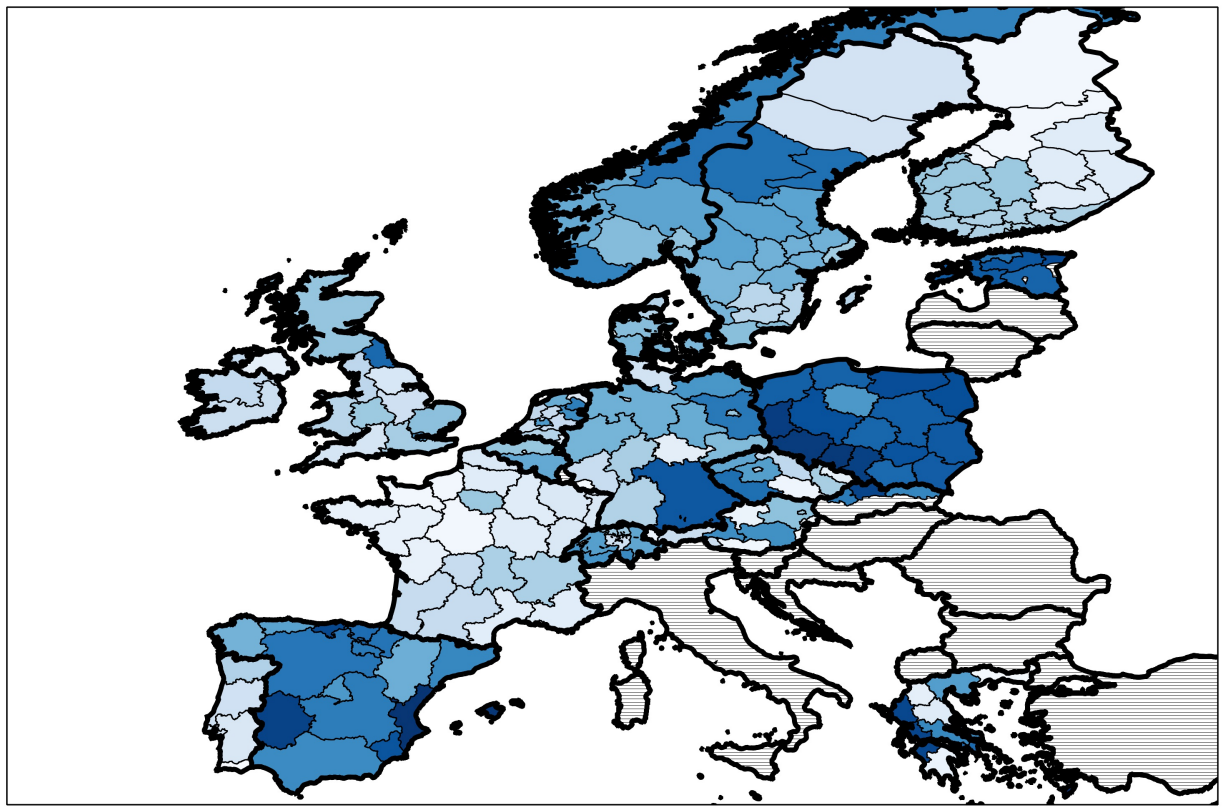

FiguRE II

Changes in Happiness Following the 2004 Madrid Terrorist Attacks This figure represents the change in happiness from before the March 11, 2004 Madrid train bombing to after. Darker colors represent greater relative decreases in happiness. Data are from the European Social Survey 2002-2011. Regions with horizontal lines are not included in the sample, and the regions of Bosnia and Herzegovina, Montenegro, and Macedonia are not available. Copyright EuroGeographics for the administrative boundaries. 


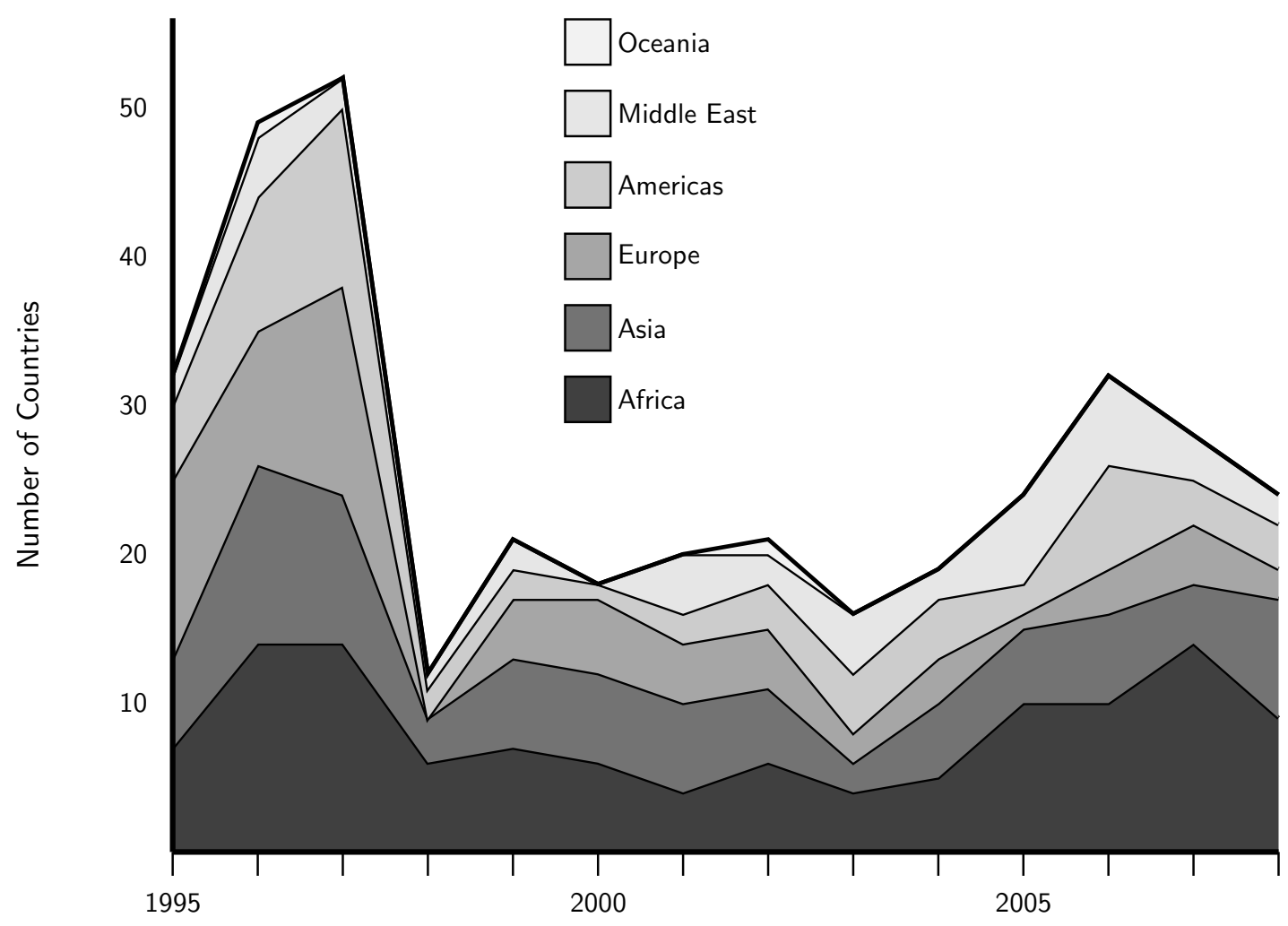

Figure III

Number of Countries Experiencing Abnormal Levels of Terrorism

This figure presents the time series of abnormal levels of terrorist attacks for 170 countries from 1995 to 2008. A country is recorded as having an abnormal level of terrorist attacks in a given year if the number of fatalities from terrorist attacks, normalized by population, exceeds the median number of fatalities over the prior five years. Only attacks with at least one fatality are included in the sample. Data are from the Global Terrorism Database. Countries are grouped according to the United Nations Country Groups. There are 46 countries in Africa, 37 countries in the Americas, 30 countries in Asia, 39 countries in Europe, 12 countries in the Middle East, and 6 countries in Oceania. 


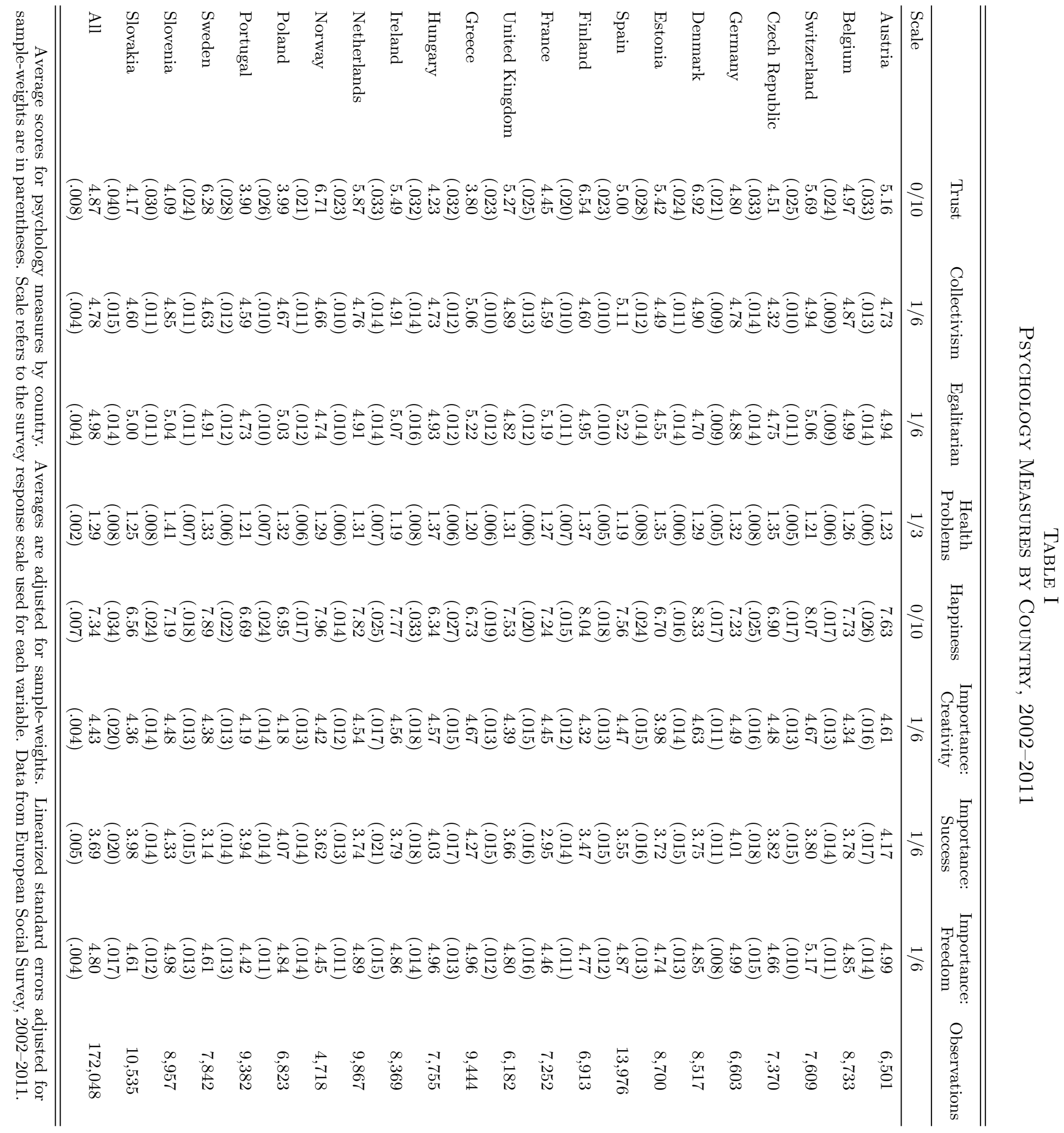




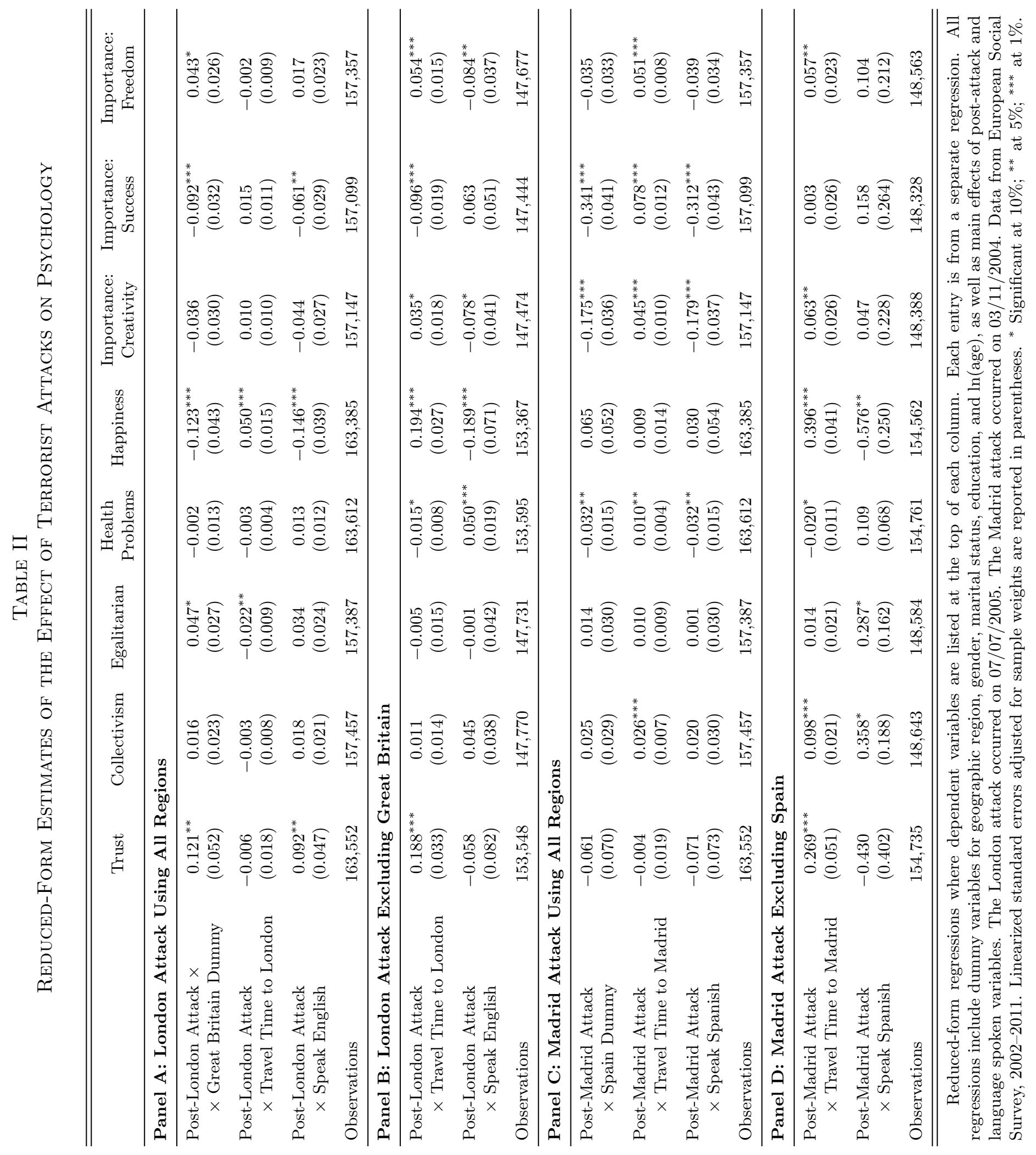




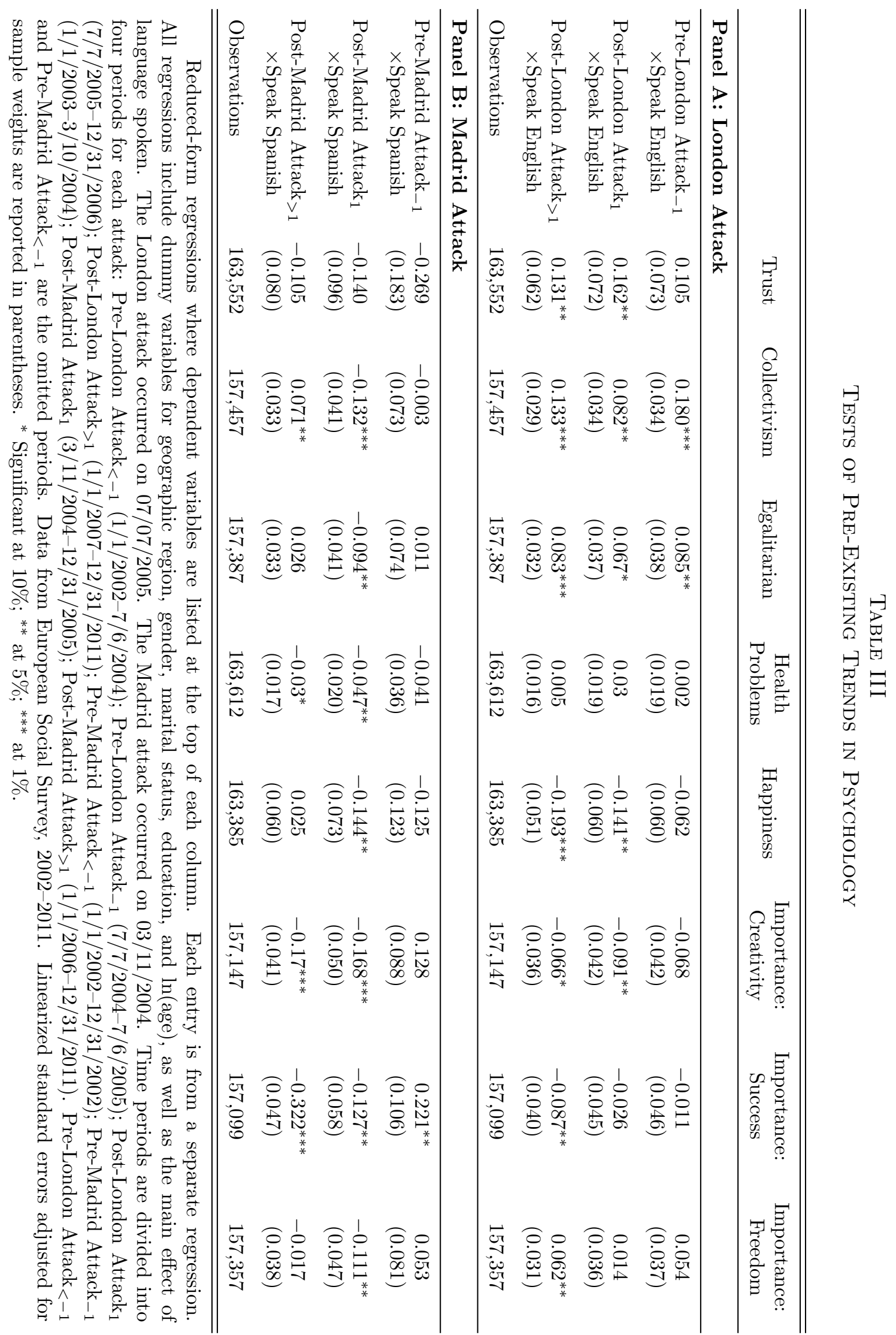




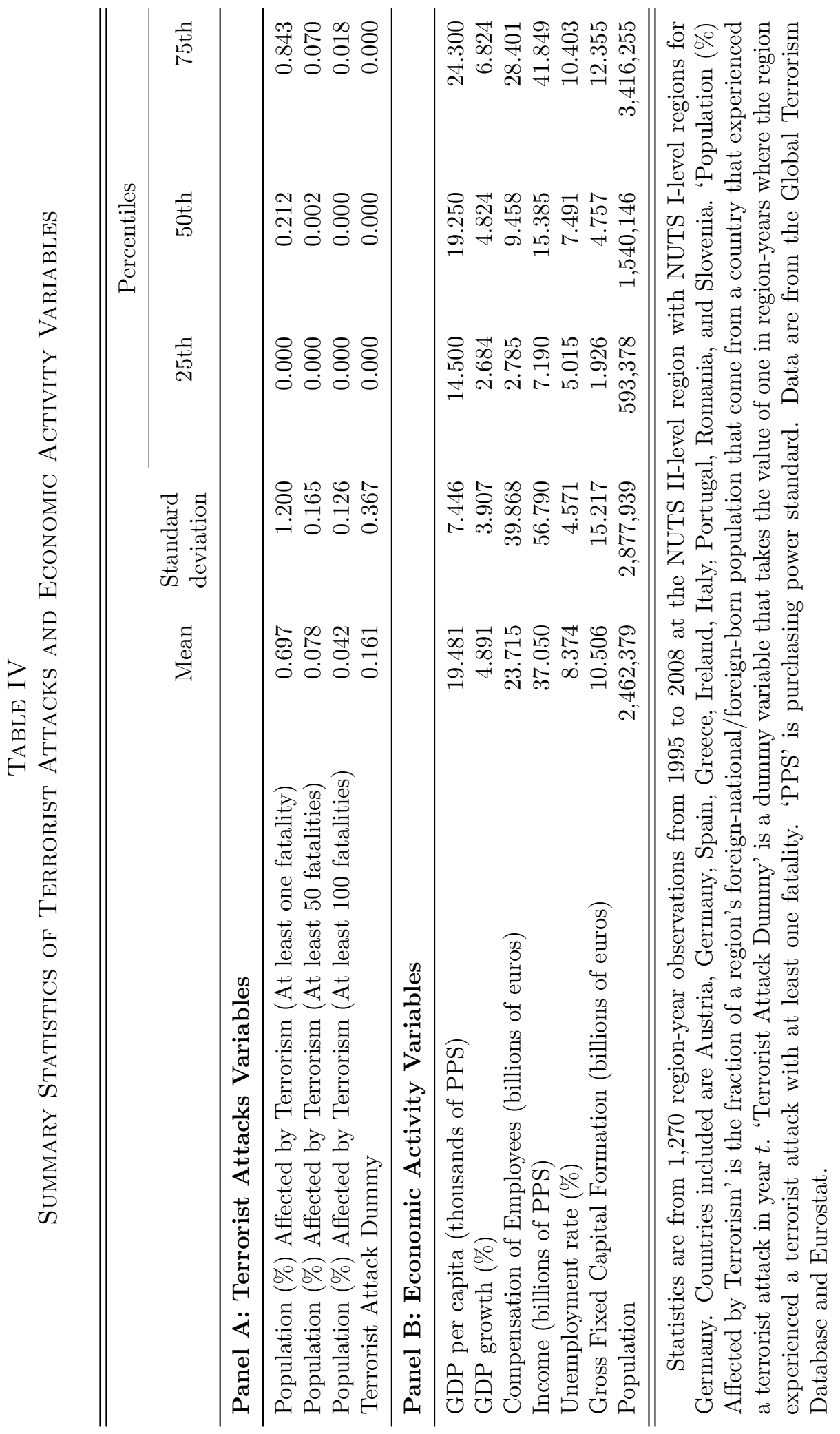




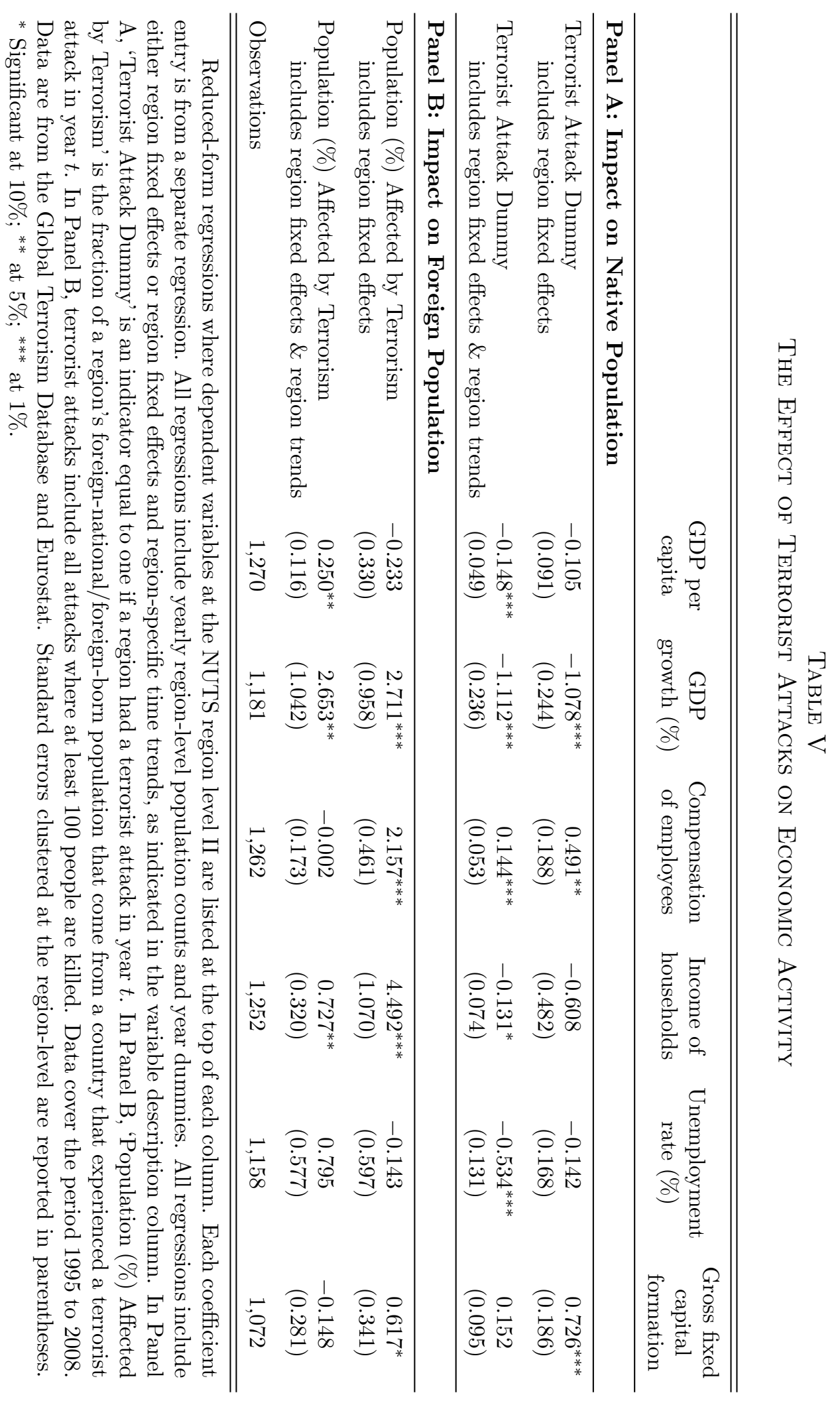


THE IMPORTANCE OF PSYCHOLOGY IN ECONOMIC ACTIVITY

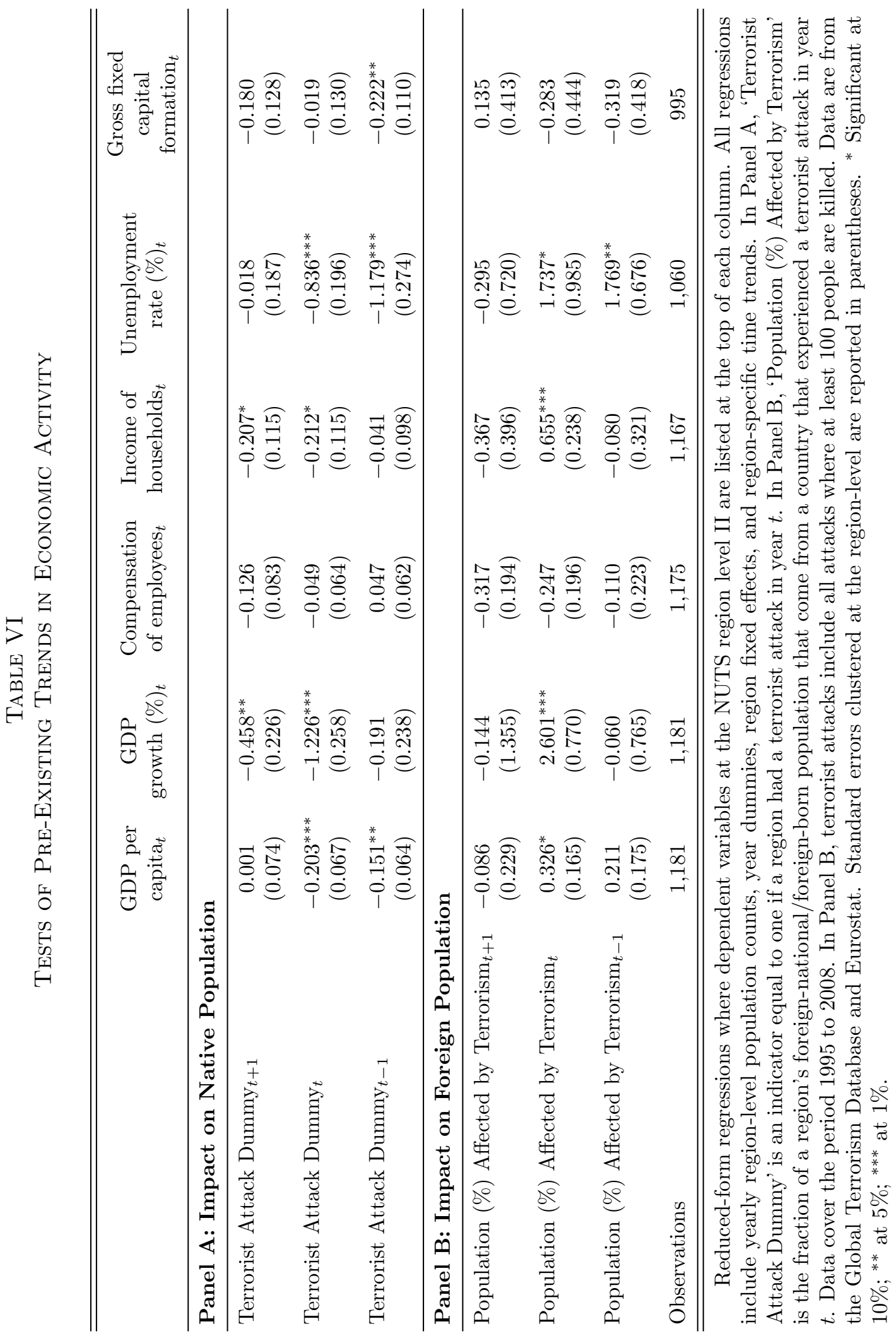




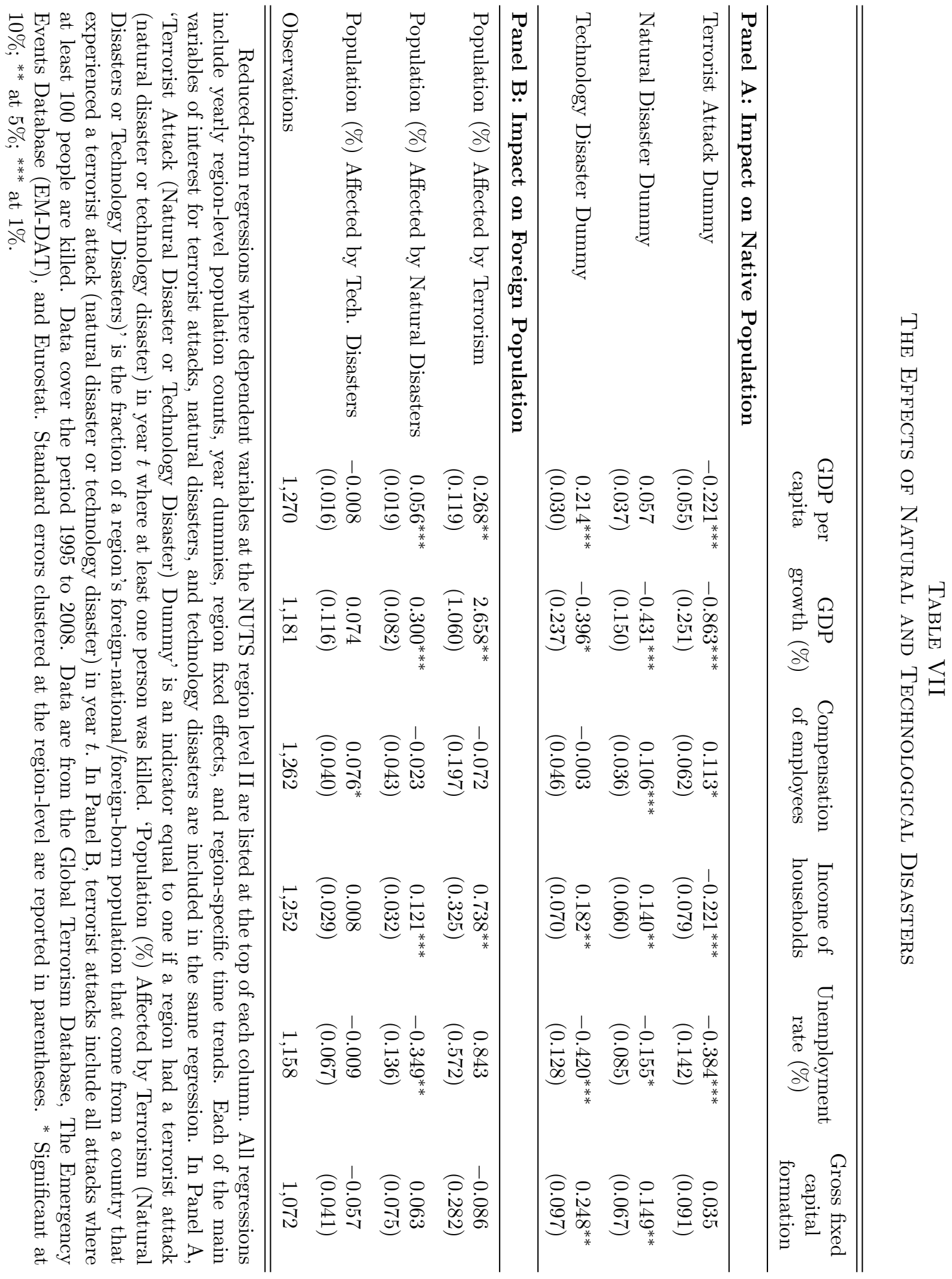




\section{For Online Publication:}

\section{Supplementary Material for}

\section{"The Importance of Psychology in Economic Activity: EVIDENCE FROM TERRORIST ATTACKS"}

This Online Appendix provides more detail on data sources and presents additional tests discussed in the paper.

\section{Principle Survey Questions}

The following lists the questions from the European Social Survey (ESS) used to measure psychological traits. In some cases, I reversed the ordering of responses ('Not like me at all,' ..., 'Very much like me') from the original data in the ESS to make all variables have response scales that are increasing in the particular trait.

Trust: Generally speaking, would you say that most people can be trusted, or that you can’t be too careful in dealing with people?

0. You can't be too careful

to

10. Most people can be trusted

Collectivism: Please tell me how much this person is or is not like you. It's very important to her/him to help the people around her/him. She/he wants to care for their well-being.

1. Not like me at all

2. Not like me

3. A little like me

4. Somewhat like me

5. Like me

6. Very much like me 
Egalitarianism: Please tell me how much each person is or is not like you. She/he thinks it is important that every person in the world should be treated equally. She/he believes everyone should have equal opportunities in life.

1. Not like me at all

2. Not like me

3. A little like me

4. Somewhat like me

5. Like me

6. Very much like me

Health Problems: Are you hampered in your daily activities in any way by any longstanding illness, or disability, infirmity or mental health problem?

1. No

2. Yes to some extent

3. Yes a lot

Happiness: Taking all things together, how happy would you say you are?

0. Extremely unhappy

to

10. Extremely happy

Importance: Creativity: Please tell me how much this person is or is not like you. Thinking up new ideas and being creative is important to her/him. She/he likes to do things in her/his own original way.

1. Not like me at all

2. Not like me

3. A little like me

4. Somewhat like me

5. Like me

6. Very much like me 
Importance: Success: Please tell me how much this person is or is not like you. Being very successful is important to her/him. She/he hopes people will recognize her/his achievements.

1. Not like me at all

2. Not like me

3. A little like me

4. Somewhat like me

5. Like me

6. Very much like me

Importance: Freedom: Please tell me how much this person is or is not like you. It is important to her/him to make her/his own decisions about what she/he does. She/he likes to be free and not depend on others.

1. Not like me at all

2. Not like me

3. A little like me

4. Somewhat like me

5. Like me

6. Very much like me 
TABLE A.1

Citizenship of Central Macedonia

\begin{tabular}{lrll}
\hline \hline Greece & 93.9740 & Spain & 0.0107 \\
Albania & 2.6382 & Philippines & 0.0096 \\
Georgia & 1.0543 & Lebanon & 0.0096 \\
Russia & 0.4666 & Syria & 0.0096 \\
Bulgaria & 0.2629 & Jordan & 0.0090 \\
Armenia & 0.1841 & Switzerland & 0.0079 \\
Germany & 0.1796 & Belarus & 0.0073 \\
Cyprus & 0.1610 & Egypt & 0.0062 \\
Australia & 0.1362 & Slovakia & 0.0062 \\
USA & 0.0918 & Bosnia and Herzegovina & 0.0056 \\
Yugoslavia & 0.0777 & South Africa & 0.0045 \\
Ukraine & 0.0749 & Portugal & 0.0039 \\
Sweden & 0.0642 & Venezuela & 0.0028 \\
Italy & 0.0569 & Denmark & 0.0028 \\
Romania & 0.0563 & Brazil & 0.0023 \\
United Kingdom & 0.0552 & China & 0.0023 \\
Kazakhstan & 0.0467 & Finland & 0.0023 \\
Canada & 0.0372 & Pakistan & 0.0017 \\
Czech Republic & 0.0321 & Ghana & 0.0011 \\
Turkey & 0.0315 & Dominica & 0.0011 \\
Poland & 0.0304 & Colombia & 0.0011 \\
Uzbekistan & 0.0225 & India & 0.0011 \\
France & 0.0214 & Sri Lanka & 0.0011 \\
Netherlands & 0.0203 & Norway & 0.0011 \\
Austria & 0.0163 & New Zealand & 0.0011 \\
Hungary & 0.0158 & Morocco & 0.0006 \\
Belgium & 0.0158 & Iran & 0.0006 \\
Moldova & 0.0141 & Iraq & 0.0006 \\
Nigeria & 0.0124 & Ireland & 0.0006 \\
\hline \hline
\end{tabular}

Percentage of individuals by citizenship in the NUTS Level II region of Central Macedonia (GR12 Kentriki Makedonia). Data are from the 2001 sample of the Greek Census from IPUMS-I. 


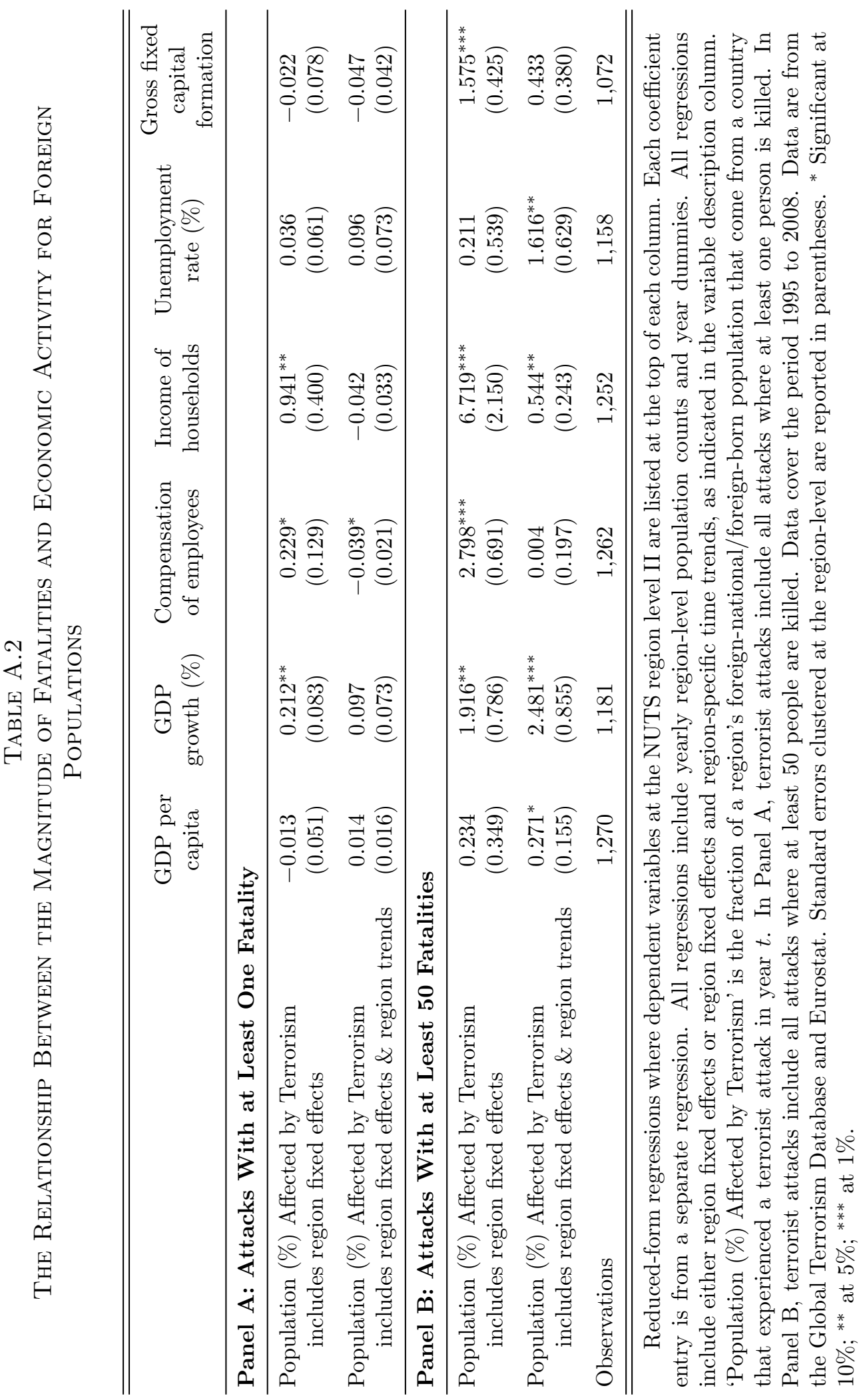




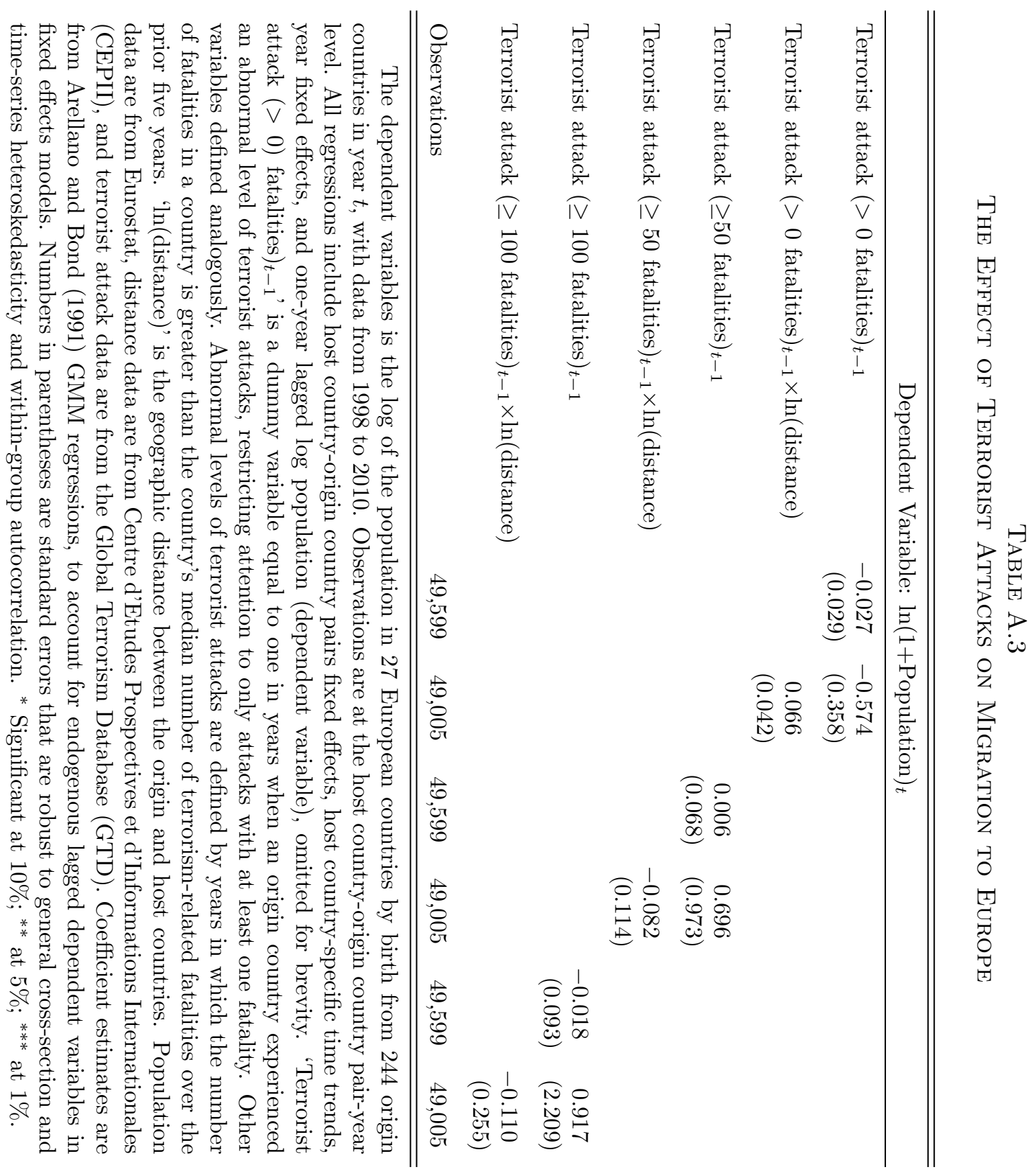

